\title{
Theoretical and Experimental Analysis of Aerodynamic Noise in Small Wind Turbines
}

\author{
José R. Dorrego ${ }^{1} \mathbb{D}$, Armando Ríos ${ }^{1}{ }^{\mathbb{D}}$, Quetzalcoatl Hernandez-Escobedo ${ }^{2} \mathbb{D}$, Rafael Campos-Amezcua ${ }^{3} \mathbb{D}$, \\ Reynaldo Iracheta ${ }^{4}$ (D) Orlando Lastres ${ }^{5}$, Pascual López ${ }^{5}$, Antonio Verde ${ }^{5}$ (D) Liliana Hechavarria ${ }^{1}$, \\ Miguel-Angel Perea-Moreno ${ }^{6}$ (D) and Alberto-Jesus Perea-Moreno ${ }^{7, * \mathbb{D}}$
}

\section{check for}

updates

Citation: Dorrego, J.R.; Ríos, A.; Hernandez-Escobedo, Q.;

Campos-Amezcua, R.; Iracheta, R.;

Lastres, O.; López, P.; Verde, A.;

Hechavarria, L.; Perea-Moreno,

M.-A.; et al. Theoretical and

Experimental Analysis of

Aerodynamic Noise in Small Wind

Turbines. Energies 2021, 14, 727.

https://doi.org/10.3390/

en14030727

Academic Editor: David Wood

Received: 30 December 2020

Accepted: 27 January 2021

Published: 30 January 2021

Publisher's Note: MDPI stays neutral with regard to jurisdictional claims in published maps and institutional affiliations.

Copyright: (c) 2021 by the authors. Licensee MDPI, Basel, Switzerland. This article is an open access article distributed under the terms and conditions of the Creative Commons Attribution (CC BY) license (https:// creativecommons.org/licenses/by/ $4.0 /)$.
1 División de Estudios de Posgrado, Universidad del Istmo, Oaxaca 70760, Mexico; r.dorrego.63@hotmail.com (J.R.D.); ruizarmando131@gmail.com (A.R.); lihed@live.com (L.H.)

2 Escuela Nacional de Estudios Superiores unidad Juriquilla, UNAM, Querétaro 76230, Mexico; qhernandez@unam.mx

3 Tecnológico Nacional de México/Centro Nacional de Investigación y Desarrollo Tecnológico, Interior Internado Palmira S/N, Col. Palmira, Morelos 62490, Mexico; rafael.ca@cenidet.tecnm.mx

4 Cátedras-CONACYT-UNISTMO, Universidad del Istmo, Oaxaca 70760, Mexico; reynaldo.iracheta@cimat.mx

5 Instituto de Investigación e Innovación en Energías Renovables, Universidad de Ciencias y Arte del Estado de Chiapas, Ciudad Universitaria, Libramiento Norte Poniente No. 1150, Chiapas 29039, Mexico; olastres@hotmail.com (O.L.); pascual.lopez@unicach.mx (P.L.); anvea@ier.unam.mx (A.V.)

6 Graduate School of Engineering and Technology, Universidad Internacional de La Rioja (UNIR), Av. de la Paz, 137, Logroño, 26006 La Rioja, Spain; miguelangel.perea@unir.net

7 Departamento de Física Aplicada, Radiología y Medicina Física, Universidad de Córdoba, Campus de Rabanales, 14071 Córdoba, Spain

* Correspondence: g12pemoa@uco.es

\begin{abstract}
This paper presents an analysis of sound pressure levels through theoretical modeling and experimental validation in a $1 \mathrm{~kW}$ small wind turbine. The models used in the theoretical analysis are BPM (Brooks, Pope, and Marcolini) and BM (Brooks and Marcolini), where wind turbine blades are divided in sections, and each section has its own contribution with respect to the total emitted sound pressure level. The noise propagation study and its experimental validation were accomplished within the requirements of the standard IEC 61400-11 Ed.3 and the standard NOM-081-SEMARNAT1994. The comparative study of theoretical and experimental results showed that the BPM and BM methods have a maximum error of $5.5 \%$ corresponding to the rated wind speed of $10 \mathrm{~m} / \mathrm{s}$. However, at low wind speeds, the theoretical models fit well to experimental data, for example, in the range from 5 to $8 \mathrm{~m} / \mathrm{s}$. The experimental data showed that the rotor's aerodynamic noise is more evident at low wind speed, because under these conditions, environmental noise is much less than wind turbine noise. Finally, to prevent possible negative effects on people's health, there is a recommended minimum and suitable distance between small wind turbine installations and buildings.
\end{abstract}

Keywords: sound pressure level; aeroacoustic; boundary layer; noise emission; aerodynamic profile; small wind turbine

\section{Introduction}

Wind energy has been the fastest expanding renewable energy in the world. Now in addition to observing them in the sea and large areas of land, you can see small wind turbines in rural communities, which have been used not only for power generation but also for water extraction. Some authors such as Schmidt and Klokker [1] maintain that people living near wind farms have serious health problems due to noise; Saab-Junior [2] evaluated several airfoils with the Qblade program and were able to minimize the noise with this evaluation.

One of the problems that small wind turbines present is the noise they emit; according to Ma et al. [3], the design of airfoils is fundamental to reduce noise and is achieved by 
analyzing the wind speed at the tip of the blade. It can be considered that the cause of noise can be aerodynamic or mechanical, as stated by Zhang et al. [4], who mention that wind turbines should be seen as a noise generation device. Clifton-Smith [5] used the numerical optimization technique denoted as a differential evolution by joining an empirical model of noise prediction with the blade element momentum, thus obtaining a design tip speed ratio of 5.5 and a reduction of $2 \mathrm{dBA}$, where it was concluded that this noise reduction was obtained by increasing the attack angle and Reynolds number.

According to Wagner et al. [6], the mechanical noise is generated by the components of the nacelle; these are very loud and can damage the human ear. However, they can be reduced by correctly isolating the nacelle, although in small wind turbines this noise is minimal, or it can be reduced efficiently by well-known engineering methods [7]. Regarding the aerodynamic noise, Deshmukh et al. [8] mention that this type of noise is produced by the friction between the wind and the blades, which produces turbulence, so the design of the airfoil also influences the generation of noise in the blades.

Several studies on noise in small wind turbines have been made, such as the one made by Ottermo et al. [9] to a $200 \mathrm{~kW}$ vertical axis wind turbine using microphones in four different positions at hub height, producing a noise map with frequencies from $500 \mathrm{~Hz}$ to $4 \mathrm{kHz}$; Möllerström et al. [10] used a $200 \mathrm{~kW}$ vertical axis wind turbine to determine the noise source and were able to compare their vertical axis wind turbine with a horizontal axis wind turbine, where they found that inlet turbulence can be a major cause of noise. Su et al. [11] also analyzed a vertical axis wind turbine, obtaining as results that thickness and load noise are the important noise sources. Chrysochoidis-Antsos et al. [12] conducted a wind resource assessment study for micro wind turbines, and they found that the azimuth of the acoustic barrier, expressed in wind field rotation angles, was found to be influential and resulted in changes of $50 \%$ to $130 \%$ with respect to annual energy yield. An analysis of the influence of wind and wind turbine tower structure on noise generation has been carried out by Zagubien and Wolniewicz [13], where they found that tall wind turbines with lattice towers emit much lower acoustic noise levels than those with tubular towers. Göçmen and Özerdem [14] analyzed six airfoils for a $10 \mathrm{~kW}$ wind turbine, and they adjusted the airfoils to decrease the noise and increase the efficiency of the wind turbine. An analysis made by Lee and Lee [15] show how a low Reynolds number associated with non-linear aerodynamic characteristics in the tip speed ratio influences the performance of a wind turbine and the noise generation. A semi-empirical acoustic model made by Zhu et al. [16] was made to predict the acoustic level of a wind turbine by dividing the blades into twodimensional airfoils, which were used to calculate the noise. An experiment performed by Oerlemans and Schepers [17] used a semi-empirical model that uses only the geometry to control the operation of the wind turbine, and they found a deviation of $1-2 \mathrm{~dB}$ between the experiment and the calculated values. Rodrigues and Marta [18] used the blade element momentum to predict the blade design and a semi-empirical model to analyze the noise; they assessed the annual energy production and overall sound pressure level and found out that increasing $8.7 \%$ in production decreases noise levels to $3.5 \mathrm{~dB}$ with a $4 \%$ increase in blade weight. For the study of small wind turbines, the startup performance must be considered, as mentioned by Sessarego and Wood [19], who state that this performance must be calculated for small blades without pitch adjustment. Sessarego and Wood [19] also say that the most powerful blade is the slowest to start, and Clifton-Smith [5] found that the quietest blade was the slowest to start, while the fastest starting blade was the loudest. However, Wood [20] establishes that small wind turbines, when well designed, are extremely quiet. Solis-Gallegos et al. [21] developed an efficient prediction methodology based on the Computational Aeroacoustics Approach (CAA), where an acoustic analogy method was employed to calculate the airfoil trailing edge noise. Research conducted by Taylor et al. [22] describes the repercussions on people living near a wind farm. In this study, 12 wind farms were analyzed, and the results showed that people heard buzzing from the wind turbines, which in most cases was annoying for them. Another study done by Lee and Lee [23] analyzed a $10 \mathrm{~kW}$ wind turbine, and his noise predictions were the 
trailing edge of the turbulence boundary layer and the turbine trailing edge noise, in part of his study, he found that in small wind turbines, the trailing edge noise is an important noise generation.

In Mexico, there are norms that establish the maximum permissible limits of noise to which people may be exposed, such as the Official Mexican Norm NOM-081-SEMARNAT1994 [24] issued by the Ministry of the Environment and Natural Resources.

In this work, a study of the noise emitted by a wind turbine of $1 \mathrm{~kW}$ installed in the Isthmus of Tehuantepec, Oaxaca, Mexico, was carried out, in which the sound pressure levels produced by the detachment of the turbulent boundary layer at the trailing edge were determined using the semi-empirical method proposed by Brooks et al. [25] and the sound pressure levels due to the formation of vortexes at the tip of the blade generated by the rotation speeds of the wind turbine $[17,26]$. In order to validate the models' results, an experimental study was carried out using the recommendations of the IEC 61400-11 Standard [27]. Another study compared the noise emitted by the wind turbine for different distances from the wind turbine with the permissible values defined in the Mexican official standard NOM-081-SEMARNAT-1994 [24]. In this work, an analysis of the results of the emission values calculated with the prediction models will be carried out and then compared with the experimental data.

This work is based on an analysis of sound pressure levels through theoretical modeling and experimental validation in a small wind turbine of $1 \mathrm{~kW}$. Section 1 presents the introduction of the models on which this study is based and the state of the art of the problem of noise in small wind turbines. Section 2 shows the BPM (Brooks, Pope, and Marcolini) and BM (Brooks and Marcolini) models used in this study. Section 3 presents the case study where the noise characteristics of the $1 \mathrm{~kW}$ wind turbine are analyzed. Section 4 presents the discussion and finally shows the conclusions of the study.

\section{Methods}

Aerodynamic noise is generated by the interaction of wind turbulence with wind turbine blades. The turbulence can be originated by the atmospheric boundary layer present in the inlet flow or by the viscous flow present in the boundary layer above the surface of the blades. Figure 1 shows the typical behavior of air flow around a wind turbine blade section. According to Brooks et al. [25] and Wagner et al. [6], there are several mechanisms of aerodynamic noise in wind turbines, namely:

- Turbulent-Boundary-Layer-Trailing-Edge (TBL-TE) Noise. It is the noise that occurred due to the formation of turbulence and wakes around the trailing edge of the airfoil.

- Laminar-Boundary-Layer Vortex-Shedding (LBL-VS) Noise. It occurs when a laminar boundary layer exists on any side of an airfoil.

- Separation-Stall Noise. This noise exists where the flow is separated around the airfoil.

- $\quad$ Trailing-Edge-Bluntness Vortex-Shedding (TEB-VS) Noise. It is the noise that is formed due to the vortex shedding caused by the bluntness of the trailing edge.

- $\quad$ Tip Vortex Formation Noise.

- Turbulent inflow noise is due to the characteristics of the incoming flow.

Brooks et al. [25] and Wagner et al. [6] show in their works how this noise contribution is generated.

According to Lowson [28], there are three classes to classify the predictions methods in wind turbines. Class I models give simple estimates of the overall sound pressure level as a simple algebraic function of basic wind turbine parameters such as rotor diameter, power, and wind speed. Class II models estimate the noise based on separate consideration of the various mechanisms causing wind turbine noise. Class III models calculate the decibels produced by wind turbines using refined models describing the noise mechanism and relate them to a detailed description of the rotor geometry and aerodynamics.

Within the Class II model are the Brooks et al. BPM model [25], the Lowson model [29], and the Grosveld model [30]. For this study, the BPM model is used to determine the sound pressure levels produced by the detachment of the turbulent boundary layer at the trailing 
edge and the method developed by Brooks and Marcollini (BM) [30] for vortex formation at the tip of the blade. We selected these two sources because the blade is from a small wind turbine, which is different from the ones usually analyzed; therefore, it is not affected by the turbulent incident flow $[11,13]$.

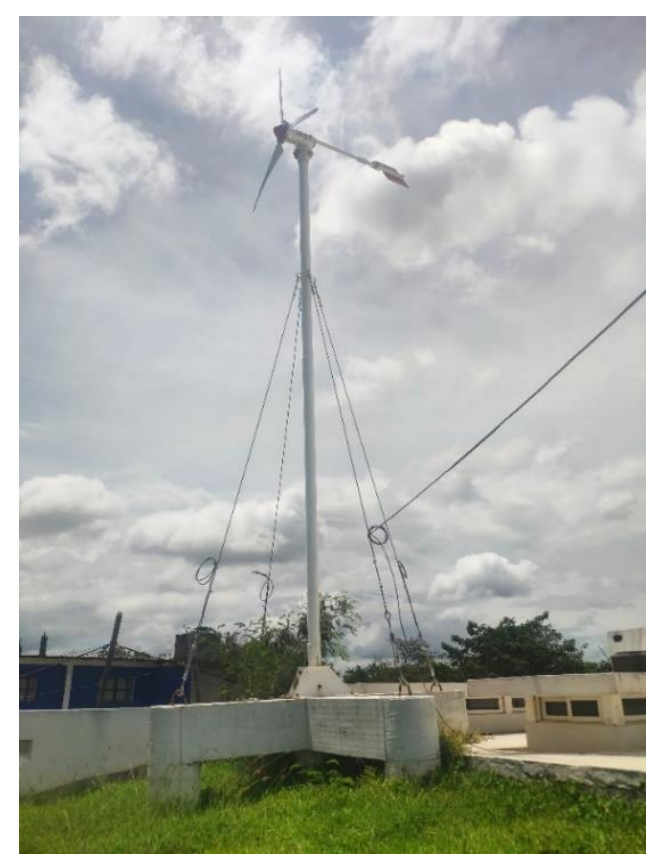

Figure 1. RTO-1kW Wind Turbine, installed in the Ejidal Bioclimatic Community Center of La Venta, Oaxaca, Mexico.

\subsection{Noise Caused by the Turbulent Boundary Layer at the Trailing Edge and by the Flow Detachment}

The noise generated by the turbulent boundary layer at the trailing edge (TBL-TE) is caused by the formation of turbulence and wakes around the trailing edge of the aerodynamic profile. Aerodynamic noise is also generated when there is flow separation over the profile wall, which occurs when the angle of attack is increased.

In the BPM model, the wind turbine blade is divided into segments, each having its own chord, length, angle of attack, and relative speed. Therefore, each segment has its own contribution to the total sound pressure level emitted. The sound pressure levels of the different blade segments must be added up to produce the sound pressure levels of each of the noise sources.

A semi-empirical model proposed by Brooks et al. [25] was used to calculate the aerodynamic noise of the small wind turbine. This model was made based on wind tunnel experiments using a NACA0012 airfoil. The BPM model predicts the total noise spectrum in a 1/3-octave presentation, which is produced by the turbulent boundary layer at the trailing edge of the profile and at the flow detachment using the following parametric equations.

$$
S P L_{\text {tot }}=10 \cdot \log \left(10^{S P L_{\alpha} / 10}+10^{S P L_{s} / 10}+10^{S P L_{p} / 10}\right)
$$

where SPL tot is the total Turbulent-Boundary-Layer-Trailing-Edge (TBL-TE) and separation noise, while the subscripts $\alpha, s$, and $p$ denote the pressure side of the aerodynamic profile, suction side of the aerodynamic profile, and the angle of attack, respectively. So, SPLP is the turbulent boundary layer trailing edge noise along the pressure side of the airfoil, SPLS is the turbulent boundary layer trailing edge noise along the suction side of the airfoil, and $S P L \alpha$ is the flow detachment noise at the leading edge of the airfoil. These are defined by 
Equations (2)-(4), respectively. Detailed descriptions of the functions and the parameters in Equations (1)-(13) are explained by Brooks et al. [25].

$$
S P L_{p}=10 \cdot \log \left(\frac{\delta_{p}^{*} \mathrm{M}^{5} L \overline{D_{h}}}{r_{e}^{2}}\right)+A\left(\frac{\mathrm{St}_{p}}{\mathrm{St}_{1}}\right)+\left(K_{1}-3\right)+\Delta K_{1}
$$

where $r_{e}$ is the observer distance, $L$ is the span section, $\delta_{p}{ }^{*}$ is the boundary layer displacement thickness based on the angle of attack and the Reynolds number, $\mathrm{M}$ is the Mach number, $\mathrm{St}_{p}$ is the Strouhal number, $\mathrm{St}_{1}$ is the Strouhal number based on the Mach number, $K_{1}$ and $\Delta K_{1}$ are amplitude functions, $A$ is an empirical function obtained from experimental tests, and $\overline{D_{h}}$ and $\overline{D_{l}}$ are high and low directivity functions.

$$
\begin{gathered}
S P L_{S}=10 \cdot \log \left(\frac{\delta_{S}^{*} \mathrm{M}^{5} L \overline{D_{h}}}{r_{e}^{2}}\right)+A\left(\frac{\mathrm{St}_{s}}{\mathrm{St}_{1}}\right)+\left(K_{1}-3\right) \\
S P L_{\alpha}=10 \cdot \log \left(\frac{\delta_{S}^{*} \mathrm{M}^{5} L \overline{D_{h}}}{r_{e}^{2}}\right)+B \frac{\mathrm{St}_{S}}{\mathrm{St}_{2}}+K_{2}
\end{gathered}
$$

where $\mathrm{St}_{2}$ is the Strouhal number based on the effective aerodynamic angle of attack, $K_{2}$ is an amplitude function, and $B$ is an empirical function obtained from experimental tests.

Detailed descriptions of the functions and the parameters in Equations (1)-(13) are explained by Brooks et al. [25].

$$
\mathrm{M}=\frac{U}{c_{0}}
$$

where $U$ is the relative wind speed and $c_{0}$ is the speed of sound.

$$
\mathrm{St}=\frac{\left(f \delta^{*}\right)}{U}
$$

where $f$ is the frequency.

$$
\begin{aligned}
& \mathrm{St}_{1}=0.02 M^{-0.6} \\
& \mathrm{St}_{2}=\mathrm{St}_{1} *\left\{\begin{array}{cl}
1, & \left(\alpha_{*} \leq 1.33^{\circ}\right) \\
10^{0.0054\left(\alpha_{*}-1.33\right)^{2},} & \left(1.33^{\circ} \leq \alpha_{*} \leq 12.5^{\circ}\right) \\
4.72, & \left(12.5^{\circ} \leq \alpha_{*}\right)
\end{array}\right.
\end{aligned}
$$

where $\alpha_{*}$ is the effective aerodynamic angle of attack.

$$
\begin{array}{r}
\mathrm{K}_{1}=\left\{\begin{array}{cc}
-4.31 \cdot \log \left(\operatorname{Re}_{c}\right)+156.3, & \left(\operatorname{Re}_{c}<2.47 \times 10^{5}\right) \\
-9 \cdot \log \left(\operatorname{Re}_{c}\right)+181.6, & \left(2.47 \times 10^{5} \leq \operatorname{Re}_{c} \leq 8 \times 10^{5}\right) \\
128.5, & \left(8 \times 10^{5}<\operatorname{Re}_{\mathrm{c}}\right)
\end{array}\right. \\
\Delta \mathrm{K}_{1}=\left\{\begin{array}{cc}
\alpha_{*}\left[1.43 \cdot \log \left(\operatorname{Re}_{\delta_{p}^{*}}\right)-5.29\right], & \left(\operatorname{Re}_{\delta_{p}^{*}} \leq 5000\right) \\
0, & \left(5000<\operatorname{Re}_{\delta_{p}^{*}}\right)
\end{array}\right. \\
\mathrm{K}_{2}=\mathrm{K}_{1}+\left\{\begin{array}{cc}
-1000, & \left(\alpha_{*}<\gamma_{0}-\gamma\right) \\
\sqrt{\beta^{2}-(\beta / \gamma)^{2}\left(\alpha_{*}-\gamma_{0}\right)^{2}}+\beta_{0}, & \left(\gamma_{0}-\gamma \leq \alpha_{*} \leq \gamma_{0}+\gamma\right) \\
-12, & \left(\gamma_{0}+\gamma<\alpha_{*}\right)
\end{array}\right.
\end{array}
$$

where

$$
\left.\begin{array}{cc}
\gamma=27.094 M+3.31 & \gamma_{0}=23.43 M+4.651 \\
\beta=72.65 M+10.74 & \beta_{0}=-34.19 M-13.82
\end{array}\right\} .
$$

The most relevant term in these equations is the argument of the logarithm. The numerical value it could take would be less than the unit (largely due to the Mach number), and therefore, the resulting logarithmic value of this term would have a negative sign. 
There is a value for the thickness of the boundary layer for each blade segment due to the variation in the length of the rope and the change in speed along the length of the blade; therefore, the Reynolds number varies in each segment.

\subsection{Noise Caused by Laminar Boundary Layer and Vortex Shedding (LBL-VS)}

When there is a laminar boundary layer on most of at least one side of an aerodynamic profile, vortex shedding noise $\left(\mathrm{SPL}_{\mathrm{LBL}-\mathrm{VS}}\right)$ can occur. Vortex shedding is apparently coupled to acoustically excited feedback loops [25]. The noise spectrum LBL-VS in the $1 / 3$ octave band is given by Equation (12).

$$
\mathrm{SPL}_{\mathrm{LBL}-\mathrm{VS}}=10 \log \left(\frac{\delta_{p}^{*} \mathrm{M}^{2} L \overline{D_{h}}}{r_{e}^{2}}\right)-G_{1}\left(\frac{S t^{\prime}}{S t_{\text {peak }}^{\prime}}\right)+G_{2}\left(\frac{\operatorname{Re}_{\mathcal{c}}}{\left(\operatorname{Re}_{c}\right)_{0}}\right)+G_{3}(\alpha)
$$

where $G_{1}, G_{2}$, and $G_{3}$ are empirical runs, $S t^{\prime}$ is the Strouhal number based on $\delta_{p}$, $S t_{\text {peak }}^{\prime}$ is the Strouhal number based on $\operatorname{Re}_{c}$, and $\mathrm{y}\left(\operatorname{Re}_{c}\right)_{0}$ is the reference Reynolds number that depends on the angle of attack.

\subsection{Noise Caused by Vortexes at the Tip of the Blade}

The prediction of noise caused by the formation of vortexes at the tip of the blade was calculated using the method proposed by Brooks and Marcolini [30]. The noise is associated with turbulence in the local flow separation region at the tip of the blade, where the vortex of the blade tip is formed. The mechanism of noise production is originated by the passage of this turbulence over the trailing edge of the profile, and it is detached toward the near wake of the rotor. The sound pressure level due to the vortex formation at the tip of the blade, $\mathrm{SPL}_{\mathrm{TIP}}$, in the 1/3 octave spectrum, is determined using Equation (13).

$$
\mathrm{SPL}_{\mathrm{TIP}}=10 \log \left(\frac{\mathrm{M}^{2} \mathrm{M}_{\text {max }}^{3} l_{\text {tip }}^{2} \overline{D_{h}}}{r_{c}^{2}}\right)-30.5(\log \mathrm{St}+0.3)^{2}+126
$$

where $l_{\text {tip }}$ is the length of the vortices at the tip of the blade; $\mathrm{M}_{\max }=U_{\max } / c_{0}$ is the maximum Mach number.

The second term on the right side of Equation (13), which gives the frequency dependence, is a parabolic fit about a peak Strouhal number of 0.5 .

\subsection{Propagation Model}

Applying the spherical propagation method, the sound pressure level is reduced by $6 \mathrm{~dB}$ per doubling of distance. This simple model must be modified in the presence of reflective surfaces and other disruptive effects [31]. To predict the sound pressure level on a specific observer at a certain distance from the wind turbine, it is necessary to determine the sound power levels of reference $\left(\mathrm{SWL}_{r e f}\right)$ of the wind turbine for different wind speeds, which is defined by Equation (14), based on a single sound source and a semispherical propagation model.

$$
\mathrm{SWL}_{r e f}=\mathrm{GM}-10 \log _{10} r_{r e f}^{2}+11
$$

where GM is the geometric mean of the sound pressure level measurements, which is define as the $\mathrm{n}^{\text {th }}$ root of the term product (Equation (15)), and $r_{r e f}$ is the reference distance, in this case $r_{r e f}=1 \mathrm{~m}$ from the source. To calculate the sound power levels, the sound pressure levels of the wind turbine must be known. When the measurements are made at great distances from the wind turbine, the sources of noise from the wind turbine can be considered as a point. Then, from the geometric mean of the sound pressure level measurements, GM, a point value for the sound pressure level of the spectrum-frequency curve can be estimated for each wind speed.

$$
\mathrm{GM}=\sqrt[n]{x_{1}+x_{2}+x_{3}+\ldots+x_{n}}
$$


where $x \mathrm{~s}$ are the measurements of the sound pressure level, and $n$ is the number of measurements.

Finally, a simple model to determine sound propagation in a free field is the spherical propagation method (Equation (16)) considering only the attenuation of the noise caused by the geometric divergence. In this case, it is considered a point source, and the effects of the earth's surface, weather effects, and obstacles, among others, are disregarded. Details of sound propagation are discussed by Vers and Beranek [32].

$$
\mathrm{SPL}=\mathrm{SWL}_{r e f}-11-20 \log (r)
$$

where SPL is the estimated propagation sound pressure level $r$, and $\mathrm{SWL}_{r e f}$ is the sound power value obtained from Equation (14).

\section{Case of Study}

As a case study, the RTO- $1 \mathrm{~kW}$ wind turbine with a diameter of $2 \mathrm{~m}$ and a nominal power of $1 \mathrm{~kW}$ was used. This wind turbine was manufactured by RTO Energy from México [33]. The study wind turbine is installed and operates in the Ejidal Bioclimatic Community Center located in the community of La Venta, Oaxaca, Mexico; see Figure 1. The low power wind turbine has a horizontal axis with a three-bladed rotor, the blades are $0.97 \mathrm{~m}$ long and were designed using the A18 aerodynamic airfoil, which presents the maximum coefficient relationship between the lift coefficient and drag coefficient respectively, $C_{l} / C_{d}$, for an optimal angle of attack $(\alpha)$ of $\alpha_{\text {opt }}=2^{\circ}$.

Figure 2 shows the curve of the rotation speed of the rotor in partial load and the output power of the wind turbine as a function of wind speed. Figure 2a shows a linear behavior of the rotation speed, with a minimum speed of $160 \mathrm{rpm}$ for $3 \mathrm{~m} / \mathrm{s}$ until reaching a maximum rotation speed of $750 \mathrm{rpm}$ for $13.5 \mathrm{~m} / \mathrm{s}$. Figure $2 \mathrm{~b}$ shows that the wind turbine begins to produce electricity at an input speed of $3 \mathrm{~m} / \mathrm{s}$, reaching a nominal power of $950 \mathrm{~W}$ at $13.5 \mathrm{~m} / \mathrm{s}$ and an output speed is $17 \mathrm{~m} / \mathrm{s}$ that is when the furling system is driven. The curves were provided by the builder RTO Energy [33].

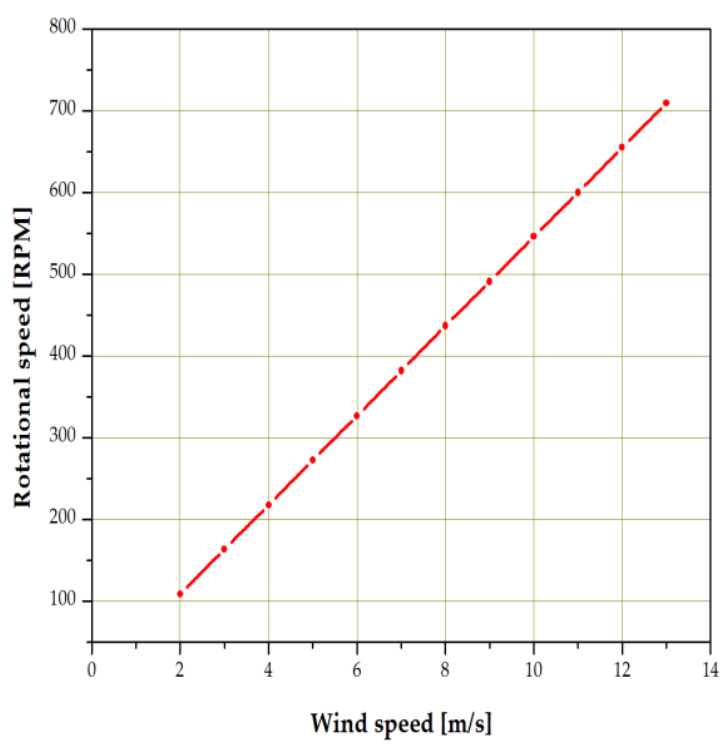

(a)

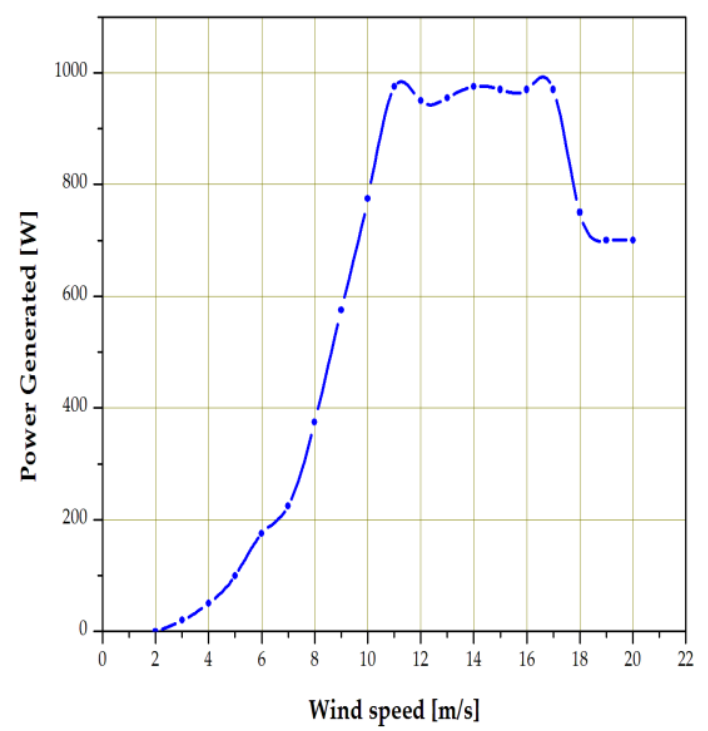

(b)

Figure 2. Characteristic curves of the Wind Turbine RTO-1kW [34]: (a) Rotation speed and (b) Output power with respect to wind speed. 


\subsection{Field Measurements of Wind Turbine Noise}

In the measurement of sound pressure levels, the area of study was characterized spatially and temporally, following the prescriptions described by Lee and Lee [23] and recommended by the IEC 61400-11 standard. The sound pressure level measurements were carried out during the day for several meteorological conditions. In all cases, significant variations in wind speed were observed at the time of measurement.

In a first instance, measurements of the noise emitted by the wind turbine were made, including the background environmental noise [34]. In a second stage, the background noise was measured at the same site, under similar environmental conditions and with the wind turbine braked, $\Omega=0 \mathrm{rpm}$.

In the first instance, and because we did not have class 1 measurement instruments, it was decided to use class 2 instruments such as the EXTECH EN300 sound level meter, with an Electret microphone from $\frac{1}{2}$ ", measurement scale from 35 to $130 \mathrm{~dB}$, automatic scale; resolution of $0.1 \mathrm{~dB}$; response frequency from 3.5 to $8000 \mathrm{~Hz}$. The accuracy of the sound level meter complies with the IEC 61400-2 Standard: A-weighting, fast response. Wind speed and temperature measurements were made with the UNI-T UT361/362 handheld anemometer.

The measurements were made according to the following steps:

1. The appropriate measurement site was selected where the presence of obstacles was minimal.

2. Then, the measuring instruments were installed at the distances recommended by the IEC 61400-11 standard [27]. It is important to mention that the place where the measurements were taken is well known for having sustained winds and almost unidirectional wind directions, from north to south [35,36].

3. Subsequently, instantaneous data were captured every 5 min, namely: Background sound pressure level $\left(\mathrm{SPL}_{\mathrm{bg}}\right)$ and sound pressure levels of the wind turbine in operation and the background ( $\left.\mathrm{SPL}_{\mathrm{wt}, \mathrm{bg}}\right)$; wind speed; temperature; pressure; relative humidity; and the time of measurement. These measurements were made during approximately one month in a daytime schedule. The measurements were made at a height of 3 meters and at 8 meters from the wind turbine.

4. Finally, databases were generated with the information collected. As an example, Table 1 shows the field measured data of the background sound pressure level over a period of approximately three hours. Table 2 shows as an example the field measured data of the sound pressure level of the wind turbine in operation and the background.

Table 1. Sample table of measured field data of the background sound pressure level.

\begin{tabular}{cccccc}
\hline $\begin{array}{c}\text { Wind Speed } \\
{[\mathbf{m} / \mathbf{s}]}\end{array}$ & $\begin{array}{c}\mathbf{S P L}_{\mathbf{b g}} \\
{[\mathbf{d B}]}\end{array}$ & $\begin{array}{c}\text { Atmospheric } \\
\text { Pressure } \\
{[\mathbf{P a}]}\end{array}$ & $\begin{array}{c}\text { Temperature } \\
{\left[{ }^{\circ} \mathbf{C}\right]}\end{array}$ & $\begin{array}{c}\text { Relative } \\
\text { Humidity } \\
{[\%]}\end{array}$ & $\begin{array}{c}\text { Time } \\
{[\mathbf{h h}: \mathbf{m m}]}\end{array}$ \\
\hline 1.9 & 45.5 & 101.3 & 35 & 34 & $12: 50$ \\
\hline 3.0 & 48.5 & 101.3 & 35 & 34 & $12: 55$ \\
\hline 2.5 & 47.4 & 101.3 & 35 & 34 & $13: 00$ \\
\hline 3.4 & 49.1 & 101.3 & 35 & 34 & $13: 05$ \\
\hline 4.6 & 50.1 & 101.3 & 35 & 34 & $13: 10$ \\
\hline 4.1 & 54.5 & 101.3 & 35 & 34 & $13: 15$ \\
\hline 4.6 & 57.1 & 101.3 & 35 & 34 & $13: 20$ \\
\hline 4.7 & 59.6 & 101.3 & 35 & 34 & $13: 25$ \\
\hline 2.7 & 51.1 & 101.3 & 35 & 34 & $13: 30$ \\
\hline 3.5 & 57.1 & 101.3 & 35 & 34 & $13: 35$ \\
\hline 2.1 & 56.3 & 101.3 & 35 & 34 & $13: 40$ \\
\hline
\end{tabular}


Table 1. Cont.

\begin{tabular}{|c|c|c|c|c|c|}
\hline $\begin{array}{c}\text { Wind Speed } \\
{[\mathrm{m} / \mathrm{s}]}\end{array}$ & $\begin{array}{c}\mathrm{SPL}_{\mathrm{bg}} \\
{[\mathrm{dB}]}\end{array}$ & $\begin{array}{c}\text { Atmospheric } \\
\text { Pressure } \\
{[\mathrm{Pa}]}\end{array}$ & $\begin{array}{c}\text { Temperature } \\
{\left[{ }^{\circ} \mathrm{C}\right]}\end{array}$ & $\begin{array}{c}\text { Relative } \\
\text { Humidity } \\
{[\%]}\end{array}$ & $\begin{array}{c}\text { Time } \\
\text { [hh:mm] }\end{array}$ \\
\hline 2.8 & 53.9 & 101.3 & 35 & 34 & $13: 45$ \\
\hline 3.0 & 51.9 & 101.3 & 35 & 34 & $13: 50$ \\
\hline 2.8 & 53.9 & 101.3 & 35 & 34 & $13: 55$ \\
\hline 1.2 & 45.8 & 101.3 & 35 & 34 & $14: 00$ \\
\hline 2.1 & 51.3 & 101.3 & 35 & 34 & $14: 05$ \\
\hline 2.3 & 51.6 & 101.3 & 35 & 34 & $14: 10$ \\
\hline 1.6 & 44.4 & 101.3 & 35 & 34 & $14: 15$ \\
\hline 1.8 & 47.7 & 101.3 & 35 & 34 & $14: 20$ \\
\hline 2.7 & 52.9 & 101.3 & 35 & 34 & $14: 25$ \\
\hline 3.1 & 55.1 & 101.3 & 35 & 34 & $14: 30$ \\
\hline 3.0 & 51.6 & 101.3 & 35 & 34 & $14: 35$ \\
\hline 2.5 & 45.8 & 101.3 & 35 & 34 & $14: 40$ \\
\hline 3.3 & 63 & 101.3 & 35 & 34 & $14: 45$ \\
\hline 1.8 & 47.3 & 101.3 & 35 & 34 & $14: 50$ \\
\hline 2.0 & 49.3 & 101.3 & 35 & 34 & $14: 55$ \\
\hline 1.9 & 45.3 & 101.3 & 35 & 34 & $15: 00$ \\
\hline 3.0 & 45.9 & 101.3 & 35 & 34 & $15: 05$ \\
\hline 2.6 & 52.2 & 101.3 & 35 & 34 & $15: 10$ \\
\hline 1.3 & 50.3 & 101.3 & 35 & 34 & $15: 15$ \\
\hline 6.3 & 53.9 & 101.3 & 35 & 34 & $15: 20$ \\
\hline 4.0 & 56 & 101.3 & 35 & 34 & $15: 25$ \\
\hline 1.2 & 52.2 & 101.3 & 35 & 34 & $15: 30$ \\
\hline
\end{tabular}

Table 2. Sample table of measured field data of the sound pressure levels of the wind turbine in operation and the background.

\begin{tabular}{cccccc}
\hline $\begin{array}{c}\text { Wind Speed } \\
{[\mathbf{m} / \mathbf{s}]}\end{array}$ & $\begin{array}{c}\mathbf{S P L}_{\mathbf{w t}, \mathbf{b g}} \\
{[\mathbf{d B}]}\end{array}$ & $\begin{array}{c}\text { Atmospheric } \\
\text { Pressure } \\
{[\mathbf{P a}]}\end{array}$ & $\begin{array}{c}\text { Temperature } \\
{\left[{ }^{\circ} \mathbf{C}\right]}\end{array}$ & $\begin{array}{c}\text { Relative } \\
\text { Humidity } \\
{[\%]}\end{array}$ & $\begin{array}{c}\text { Time } \\
{[\mathbf{h h}: \mathbf{m m}]}\end{array}$ \\
\hline 5.5 & 63.9 & 101.3 & 35 & 34 & $11: 10$ \\
\hline 3.0 & 67.4 & 101.3 & 35 & 34 & $11: 15$ \\
\hline 2.5 & 67.0 & 101.3 & 35 & 34 & $11: 20$ \\
\hline 3.0 & 72.0 & 101.3 & 35 & 34 & $11: 25$ \\
\hline 2.0 & 64.0 & 101.3 & 35 & 34 & $11: 30$ \\
\hline 7.0 & 69.0 & 101.3 & 35 & 34 & $11: 35$ \\
\hline 4.0 & 61.0 & 101.3 & 35 & 34 & $11: 40$ \\
\hline 7.5 & 62.8 & 101.3 & 35 & 34 & $11: 45$ \\
\hline 3.0 & 62.0 & 101.3 & 35 & 34 & $11: 50$ \\
\hline 4.0 & 64.0 & 101.3 & 35 & 34 & $11: 55$ \\
\hline 2.0 & 59.0 & 101.3 & 35 & 34 & $12: 00$ \\
\hline & & & & &
\end{tabular}


Table 2. Cont.

\begin{tabular}{|c|c|c|c|c|c|}
\hline $\begin{array}{c}\text { Wind Speed } \\
{[\mathrm{m} / \mathrm{s}]}\end{array}$ & $\begin{array}{c}\operatorname{SPL}_{\mathbf{w t}, \mathrm{bg}} \\
{[\mathrm{dB}]}\end{array}$ & $\begin{array}{c}\text { Atmospheric } \\
\text { Pressure } \\
{[\mathrm{Pa}]}\end{array}$ & $\begin{array}{c}\text { Temperature } \\
{\left[{ }^{\circ} \mathrm{C}\right]}\end{array}$ & $\begin{array}{c}\text { Relative } \\
\text { Humidity } \\
{[\%]}\end{array}$ & $\begin{array}{c}\text { Time } \\
\text { [hh:mm] }\end{array}$ \\
\hline 4.0 & 60.0 & 101.3 & 35 & 34 & 12:05 \\
\hline 2.5 & 57.0 & 101.3 & 35 & 34 & $12: 10$ \\
\hline 8.0 & 65.0 & 101.3 & 35 & 34 & $12: 15$ \\
\hline 7.0 & 63.0 & 101.3 & 35 & 34 & $12: 20$ \\
\hline 5.0 & 60.0 & 101.3 & 35 & 34 & $12: 25$ \\
\hline 4.6 & 63.0 & 101.3 & 35 & 34 & $12: 30$ \\
\hline 5.0 & 68.0 & 101.3 & 35 & 34 & $12: 35$ \\
\hline 2.0 & 60.0 & 101.3 & 35 & 34 & $12: 40$ \\
\hline 4.0 & 61.2 & 101.3 & 35 & 34 & $12: 45$ \\
\hline 2.3 & 56.0 & 101.3 & 35 & 34 & $12: 50$ \\
\hline 1.5 & 58.0 & 101.3 & 35 & 34 & $12: 55$ \\
\hline 2.7 & 57.0 & 101.3 & 35 & 34 & $13: 00$ \\
\hline 5.0 & 66.0 & 101.3 & 35 & 34 & $13: 05$ \\
\hline 4.0 & 62.0 & 101.3 & 35 & 34 & $13: 10$ \\
\hline 3.0 & 61.0 & 101.3 & 35 & 34 & $13: 15$ \\
\hline 5.0 & 62.0 & 101.3 & 35 & 34 & $13: 20$ \\
\hline 5.5 & 63.0 & 101.3 & 35 & 34 & $13: 25$ \\
\hline 4.0 & 67.0 & 101.3 & 35 & 34 & $13: 30$ \\
\hline 2.0 & 60.0 & 101.3 & 35 & 34 & 13:35 \\
\hline 2.3 & 63.7 & 101.3 & 35 & 34 & $13: 40$ \\
\hline
\end{tabular}

\subsection{Implementation of Aeroacoustic Models}

To carry out the aeroacoustic study, the sound pressure levels produced by the turbulent boundary layer at the trailing edge and the flow detachment were analyzed, as well as the noise generated by the laminar boundary layer at the trailing edge and the vortex detachment, as well as that caused by the formation of vortexes at the tip of the blade, which are described by the BPM and BM models, respectively, are shown in Table 3.

Table 3. Blade dimensions in the study sections.

\begin{tabular}{cccccccc}
\hline $\begin{array}{c}\text { Section } \\
{[-]}\end{array}$ & $\begin{array}{c}\text { Radius } \\
{[\mathrm{m}]}\end{array}$ & $\begin{array}{c}\text { Chord } \\
{[\mathrm{m}]}\end{array}$ & $\begin{array}{c}\text { Twist } \\
{\left[{ }^{\circ}\right]}\end{array}$ & $\begin{array}{c}\text { Section } \\
{[-]}\end{array}$ & $\begin{array}{c}\text { Radius } \\
{[\mathrm{m}]}\end{array}$ & $\begin{array}{c}\text { Chord } \\
{[\mathrm{m}]}\end{array}$ & $\begin{array}{c}\text { Twist } \\
{\left[{ }^{\circ}\right]}\end{array}$ \\
\hline 1 & 0.145 & 0.165 & 22.4 & 9 & 0.625 & 0.089 & 10.1 \\
\hline 2 & 0.205 & 0.155 & 20.9 & 10 & 0.685 & 0.079 & 8.5 \\
\hline 3 & 0.265 & 0.146 & 19.3 & 11 & 0.745 & 0.069 & 7.0 \\
\hline 4 & 0.325 & 0.136 & 17.8 & 12 & 0.805 & 0.060 & 5.4 \\
\hline 5 & 0.385 & 0.127 & 16.2 & 13 & 0.865 & 0.050 & 3.9 \\
\hline 6 & 0.445 & 0.117 & 14.7 & 14 & 0.925 & 0.041 & 2.4 \\
\hline 7 & 0.505 & 0.108 & 13.2 & 15 & 0.986 & 0.031 & 0.8 \\
\hline 8 & 0.565 & 0.098 & 11.6 & & & & \\
\hline
\end{tabular}

The wind turbine rotor blade was divided into 15 sections, which are described in Table 3. The semi-empirical models for predicting the aerodynamic noise emitted by wind 
profiles were implemented in sections $9-15$ of the wind turbine blade, the ones furthest from the center of the rotor, since their tangential speeds are higher, and therefore, their impact is more important in the generation of noise; see Figure 3.

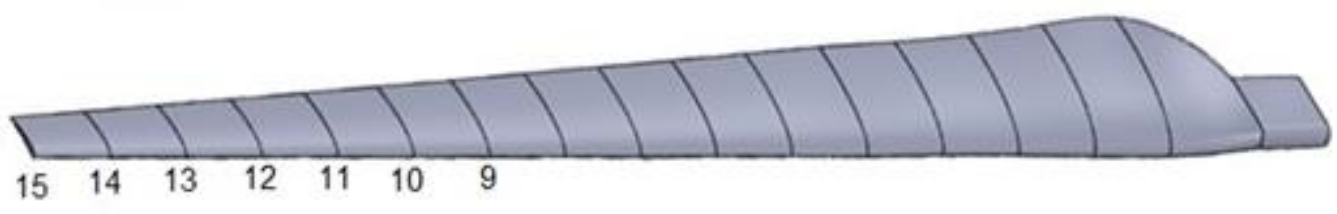

Figure 3. Elements of the wind turbine blade.

To apply the noise prediction models of an aerodynamic profile, the following procedure is applied:

1. First, the wind speeds to be evaluated are limited in this case to 5 to $10 \mathrm{~m} / \mathrm{s}$.

2. The geometry is studied, and the blade is divided into segments, selecting those closest to the tip.

3. Depending on the length of the segment to be evaluated, the relative speed at which the wind-driven segment moves is calculated.

4. Given the relative speeds and length of rope of each segment, the Reynolds numbers and Mach numbers are calculated.

5. Given this information, the thickness of the boundary layers on the suction and pressure side and their noise contribution are calculated.

6. By adding these boundary layers, the sound contribution of the selected segment is calculated.

7. Depending on the number of segments, they are added to when evaluating the sound emission of the blade.

8. Finally, to know the sound emission of the wind turbine, the number of blades of the wind turbine are added together, so we know the sound emission at the selected wind speeds.

\subsubsection{Turbulent Boundary Layer at the Trailing Edge and Flow Detachment}

Figure 4 shows the sound pressure levels with respect to the angle of attack of the airfoil, as shown in Equation (4), in a frequency spectrum from 20 to 16,000 $\mathrm{Hz}$ for section 15 and a wind speed range of 5-10 m/s. In the same figure, for higher wind speeds, sound pressure levels above $40 \mathrm{~dB}$ are found, confirming that as wind speed increases, the sound contributions from the blade increase.

Figure 4 shows the sound pressure levels emitted by the angle of attack of the A18 aerodynamic profile in a frequency spectrum from 20 to $16000 \mathrm{~Hz}$ and a speed range from 5 to $10 \mathrm{~m} / \mathrm{s}$ of incident wind speed. From the segment of position 15 of Table 3 and calculated with Equation (4) of the BPM model, it can be seen that in the wind speeds of greater magnitude and at low frequency values, there are sound pressure levels of $46.6 \mathrm{~dB}$, confirming that the wind that drives the wind turbine to blow faster, and at frequencies below $1000 \mathrm{~Hz}$, the sound contributions of the blade increase.

Figure 5 shows the contribution in the sound pressure level emitted by the pressure side of the aerodynamic profile, Equation (2), for section 15 and a wind speed range of $5-10 \mathrm{~m} / \mathrm{s}$. In the same figure, it is observed that the sound pressure levels have a very uniform behavior, being noticed that they are higher in the low frequency zone reaching $47 \mathrm{~dB}$ for speeds of $10 \mathrm{~m} / \mathrm{s}$. 


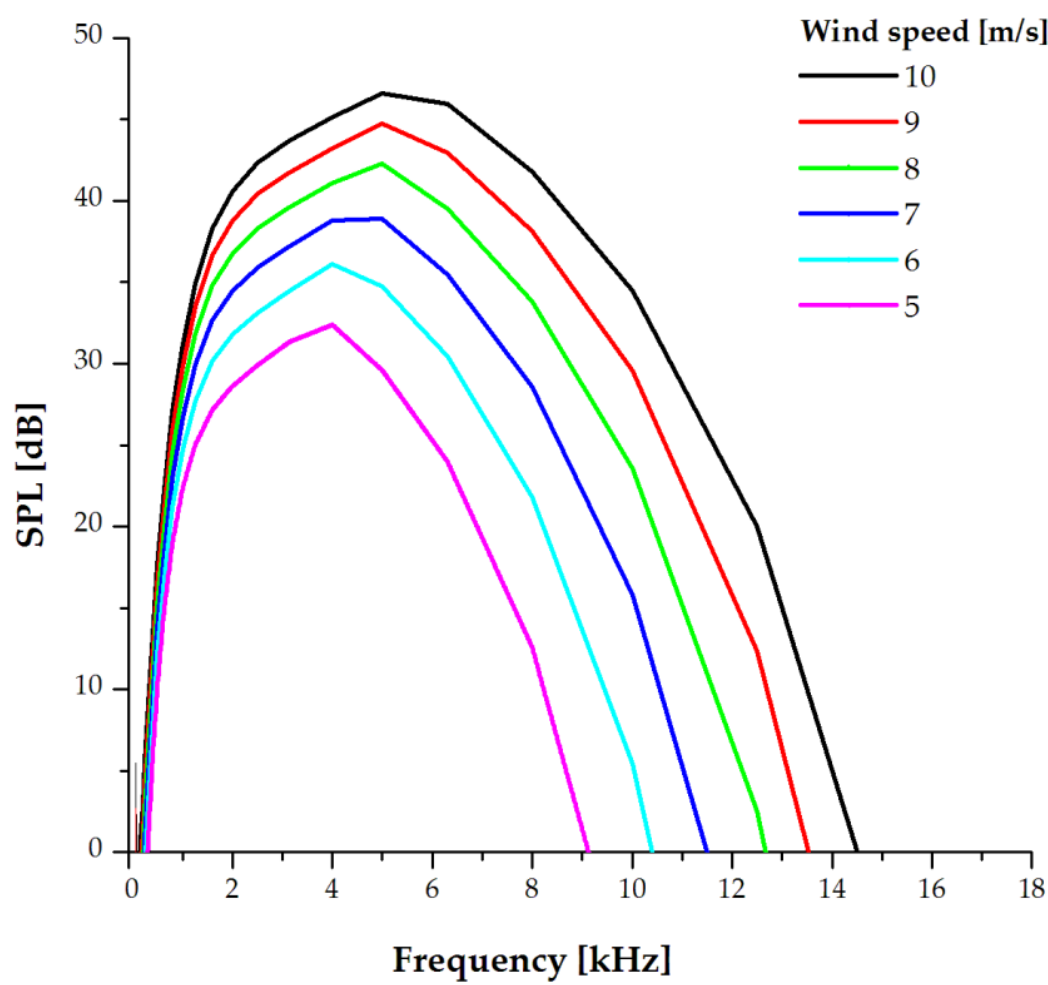

Figure 4. Contribution of sound pressure level due to stall separation $\left(S P L_{\alpha}\right)$.

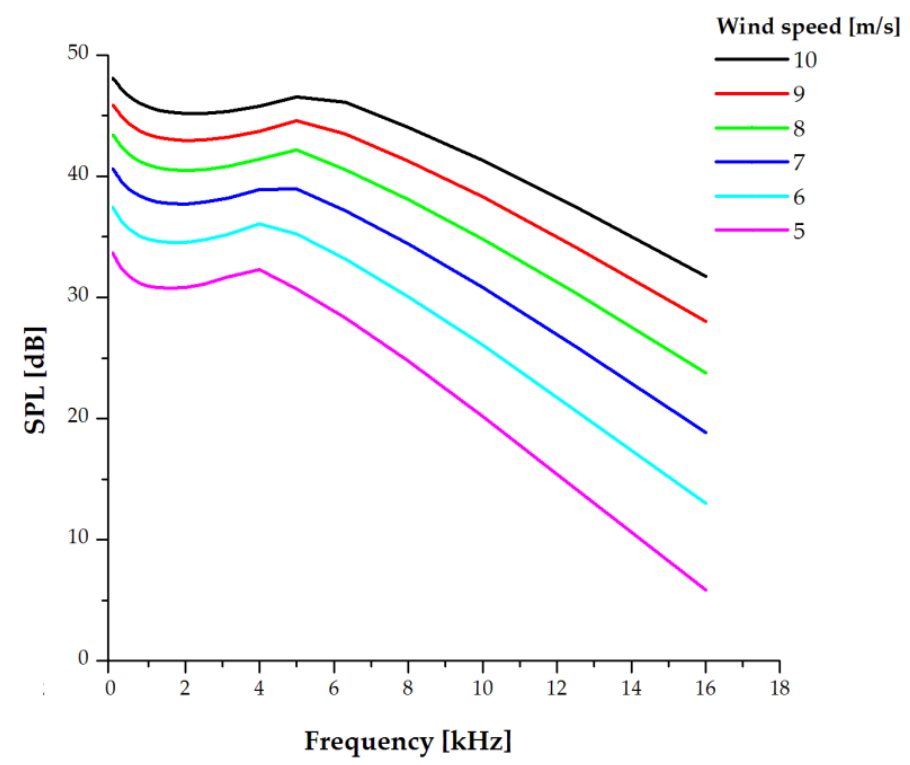

Figure 5. Sound pressure levels emitted by the pressure zone of the aerodynamic profile (SPL $)$.

Figure 6 shows the contribution in the sound pressure level emitted by the suction side of the aerodynamic profile, as shown in Equation (3), for section 15, and a wind speed range of $5-10 \mathrm{~m} / \mathrm{s}$. This phenomenon occurs because the boundary layer of the wind along the longest zone of the airfoil creates a low-pressure zone where aerodynamic lift is developed. Therefore, when the boundary layer breaks away from the trailing edge of the airfoil, it emits pressure disturbances or sound pressure levels. 


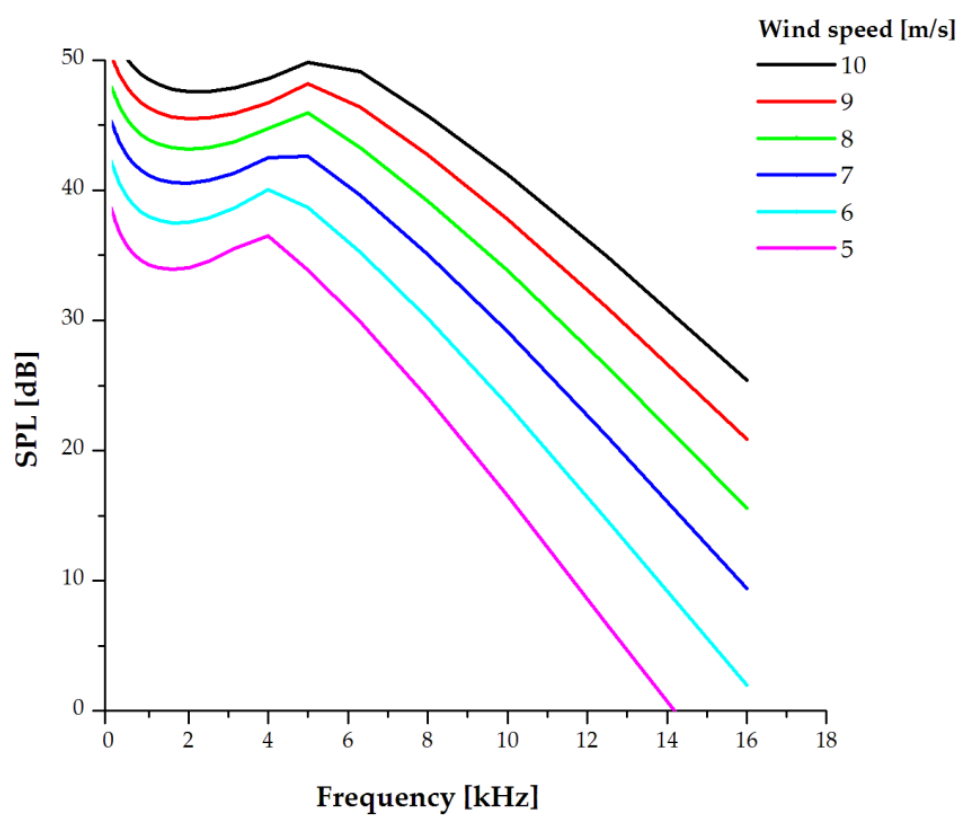

Figure 6. Sound pressure levels emitted by the suction area of the aerodynamic airfoil $\left(\mathrm{SPL}_{\mathrm{s}}\right)$.

Once data are obtained on the sound pressure levels emitted by the suction side, pressure side, and leading edge in section 15, the total sound pressure levels, as shown Equation (1) of section 15 are determined; see Figure 7.

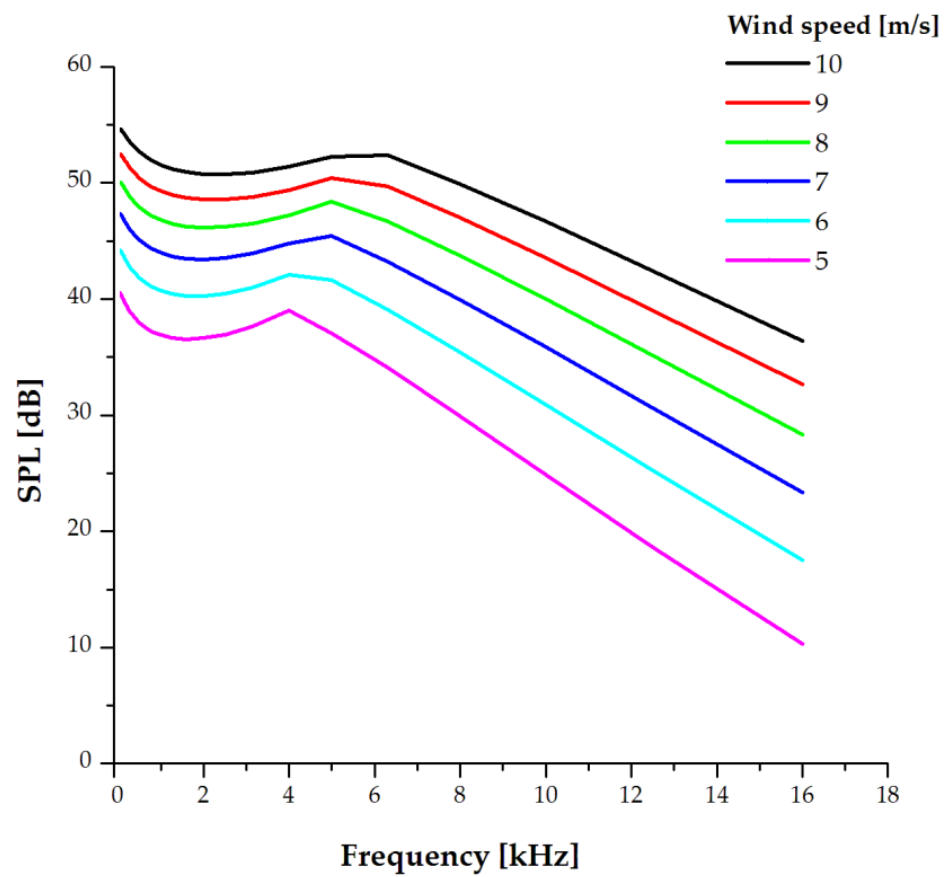

Figure 7. Total sound pressure levels $\left(\mathrm{SLP}_{\text {tot, }} \mathrm{s}\right)$.

Subsequently, the total sound pressure levels emitted by the other sections that make up the blade were determined, for example, sections 9-15 of the wind turbine blade, in Table 3, for a wind speed range that varies between 5 and $10 \mathrm{~m} / \mathrm{s}$. Figure 8 shows the sound pressure levels of each segment of the blade study at different wind speeds and frequencies, where the sound pressure level presents high values in the low-frequency ranges and showing a decrease as the frequency increases, but it also increases as the wind speed of the selected segment increases. 


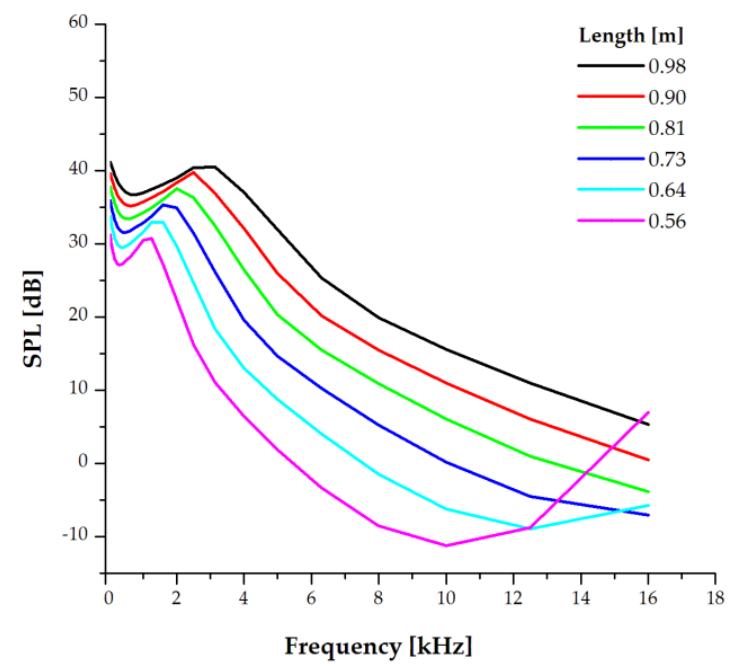

(a)

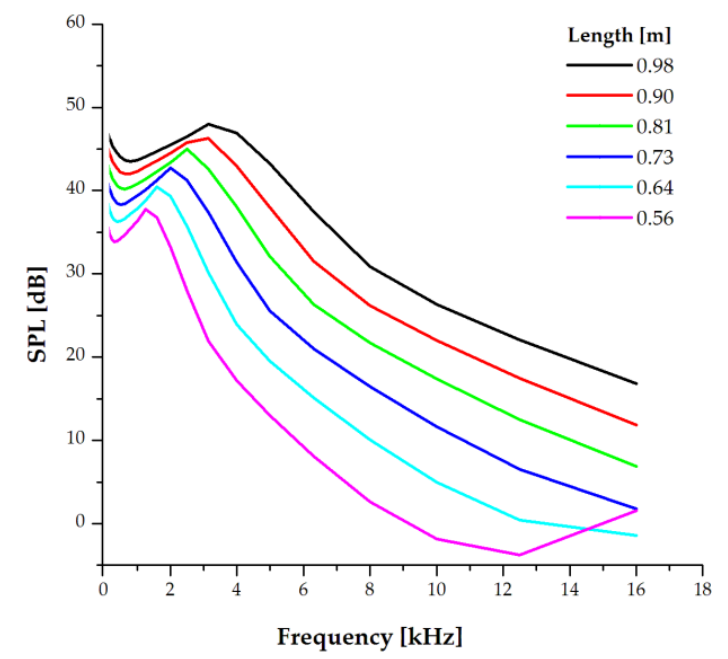

(c)

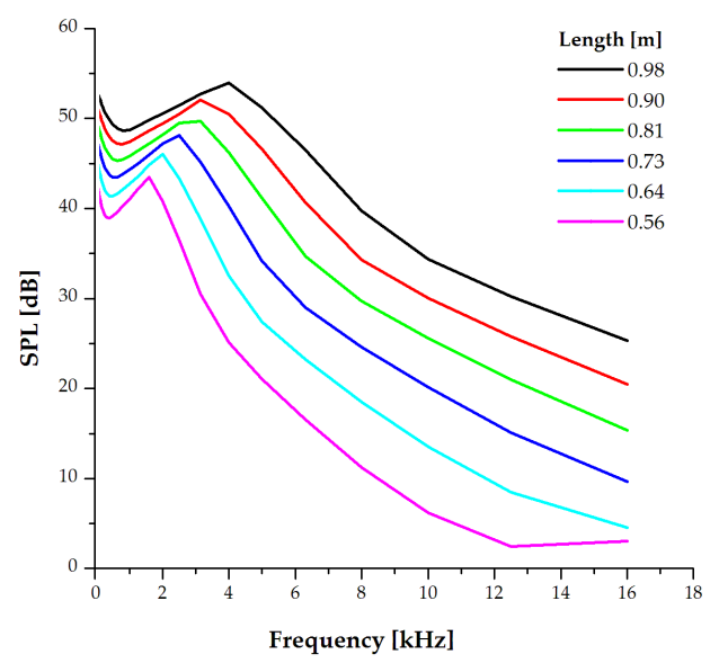

(e)

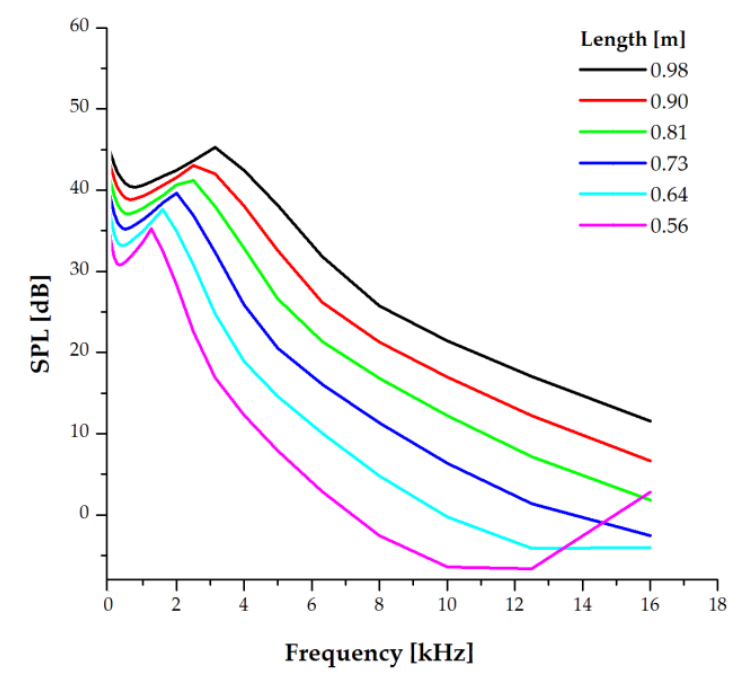

(b)

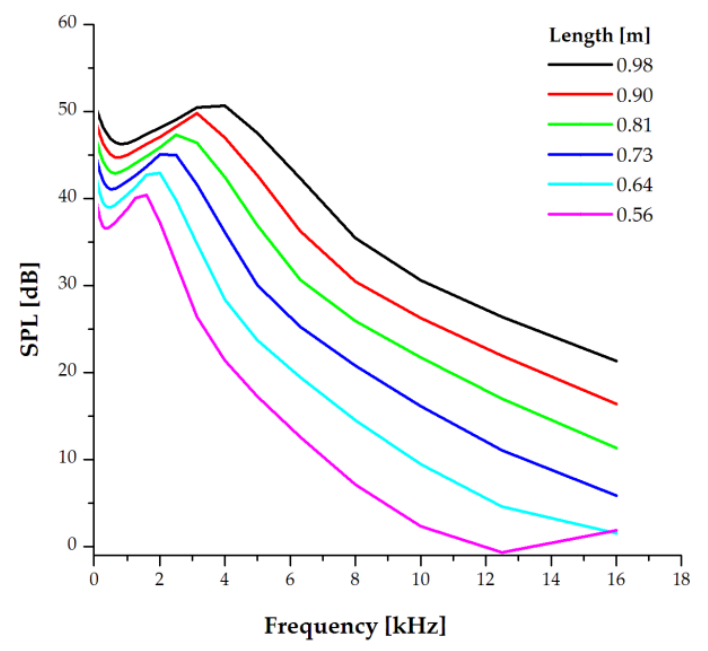

(d)

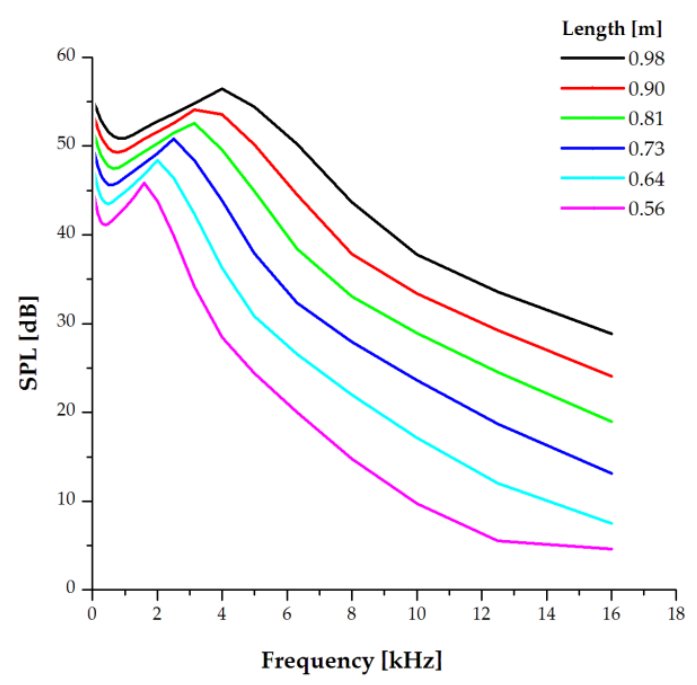

(f)

Figure 8. Emission of sound pressure levels of each segment of the blade studied for different wind speeds: (a) $5 \mathrm{~m} / \mathrm{s}$; (b) $6 \mathrm{~m} / \mathrm{s}$; (c) $7 \mathrm{~m} / \mathrm{s}$; (d) $8 \mathrm{~m} / \mathrm{s}$; (e) $9 \mathrm{~m} / \mathrm{s}$; and (f) $10 \mathrm{~m} / \mathrm{s}$. 
The contribution of the emission of the total sound pressure levels of the rotor of the wind turbine under study can be seen in Figure 9, where it is observed that for a high-speed range, the total sound pressure values are above $60 \mathrm{~dB}$.

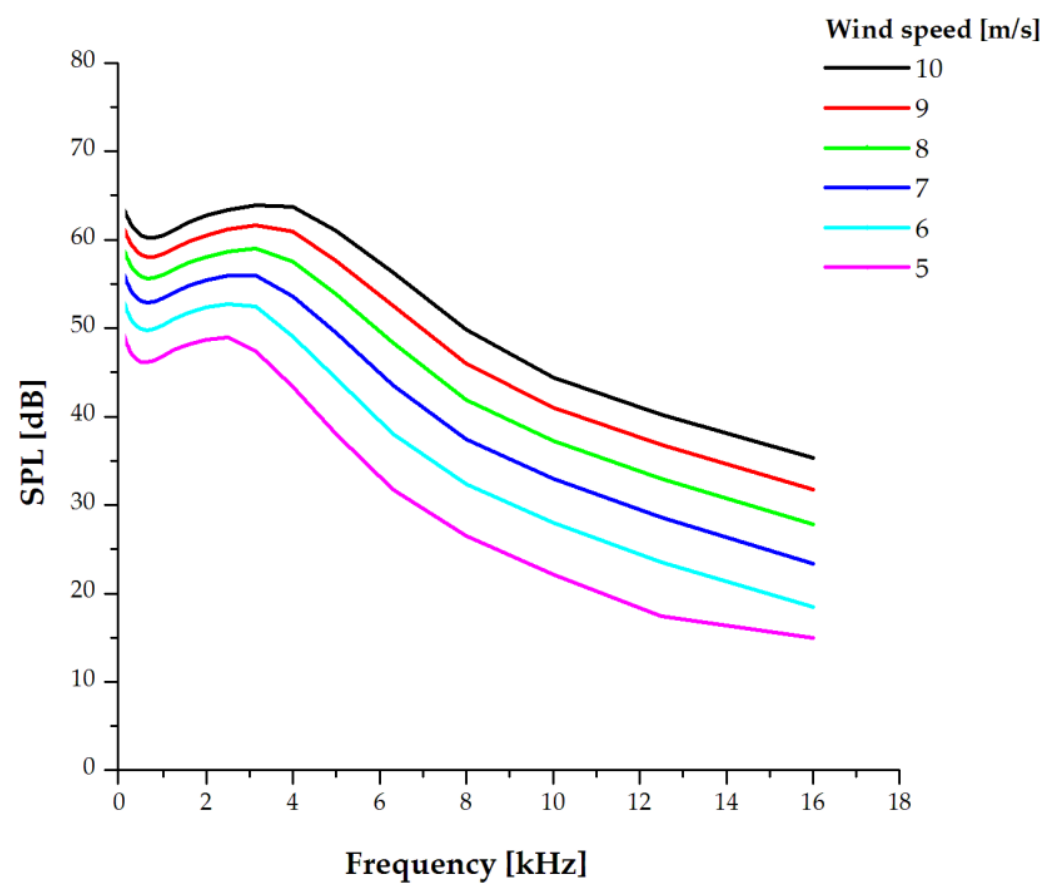

Figure 9. Emission of total rotor sound pressure levels at different wind speeds.

To adjust the frequency range of the sound pressure levels to the frequency response of the human ear, the A-weighting is used. This is a central tendency measure that is convenient to use when a dataset has a corresponding value with respect to the other data. By including the A-weighted values in the data of Figure 9, the results of the A-weighted wind turbine sound pressure levels are obtained, which are shown in Figure 10.

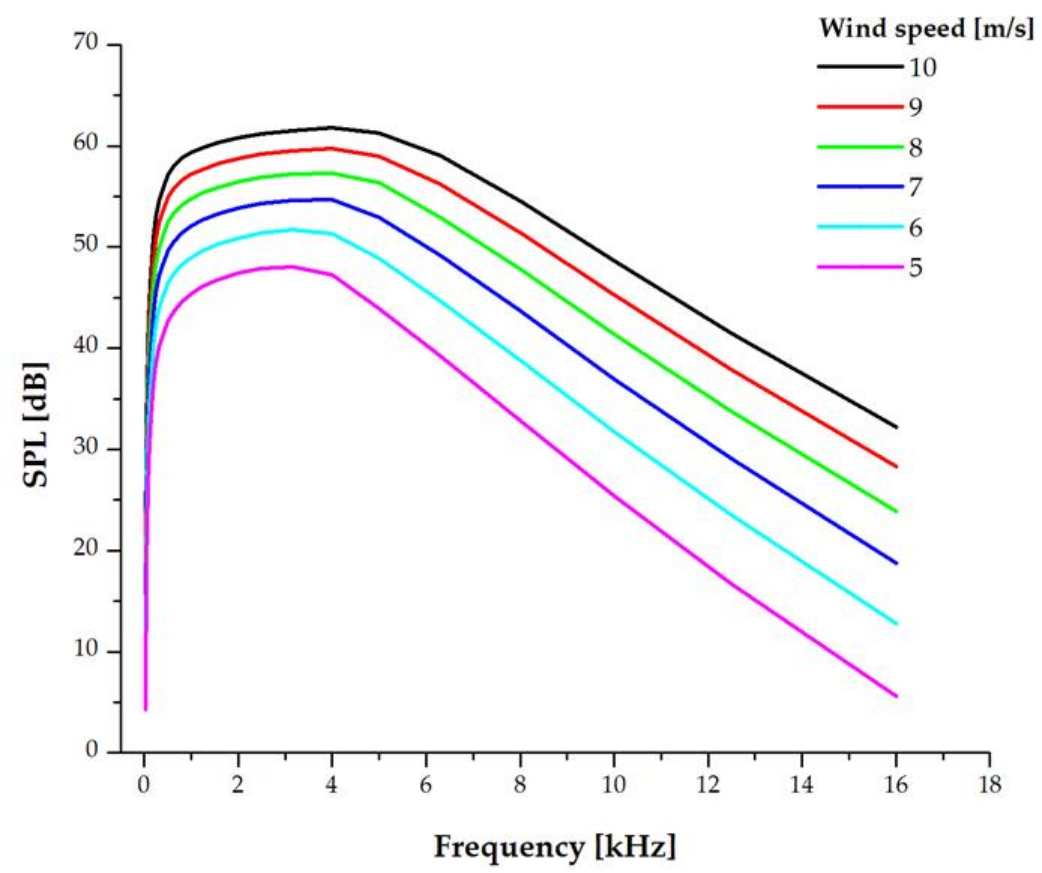

Figure 10. A-weighted wind turbine sound pressure levels. 


\subsubsection{Sound Pressure Levels Due to Vortex Formation at the Tip of the Blade}

In Figure 11, we can see the sound pressure levels due to the vortex formation at the tip of the blade for different tangential speeds of the blade tip, which were obtained using the data in Table 3, and the operating parameters of the wind turbine studied. In this figure, it is observed that as the speed at the blade tip increases, the sound contribution increases until reaching a maximum of $83 \mathrm{~dB}$.

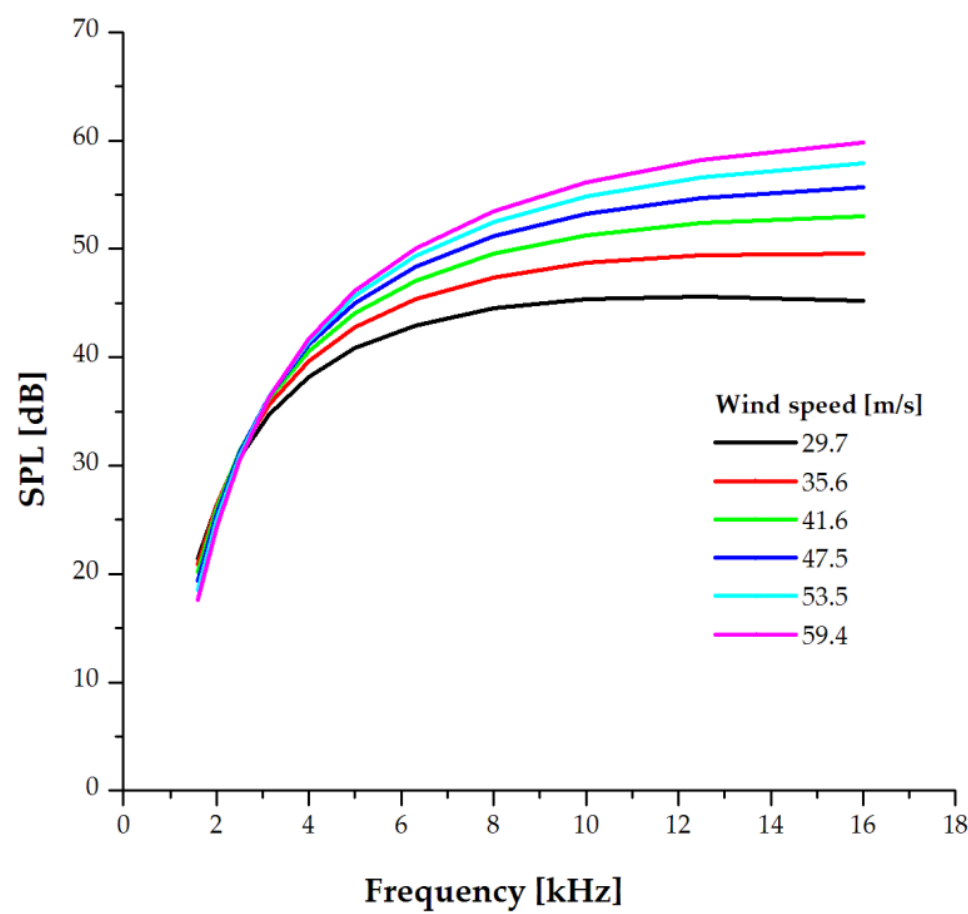

Figure 11. Sound pressure levels produced by the vortices at the tip of the blade.

To estimate the sound pressure level in a specific receiver located at a certain distance from the wind turbine, a detailed analysis of the sound pressure levels in the $1 / 3$ octave bands was carried out $[10,28]$, with the groups of parameters (independent variables) proposed by the BPM and BM models. The sound power levels for wind speeds recommended by the IEC 61400-11 standard were calculated based on it. The results can be seen in Table 4 .

Table 4. Predicted sound pressure levels and sound power at $1 \mathrm{~m}$ from wind turbine.

\begin{tabular}{ccc}
\hline Wind Speed $[\mathrm{m} / \mathbf{s}]$ & Sound Pressure Level $[\mathrm{dB}]$ & Sound Power Level [dB] \\
\hline 10 & 71.2 & 82.2 \\
\hline 9 & 71.1 & 82.2 \\
\hline 8 & 70.9 & 81.9 \\
\hline 7 & 70.0 & 81.0 \\
\hline 6 & 69.0 & 80.0 \\
\hline 5 & 67.0 & 78.0 \\
\hline
\end{tabular}

\section{Discussion}

Taking as an example the data obtained with the experimental measurements, as shown in Table 1, from which only wind speeds varying in a range of 1 to $8 \mathrm{~m} / \mathrm{s}$ were obtained, we decided to calculate the trend of the sound emission by means of a Pearson linear extrapolation model up to the wind speed of $10 \mathrm{~m} / \mathrm{s}$ (wind speed range recommended by IEC 61400-11). It is important to mention that for these measurements, the 
wind turbine was kept in a stationary position, so the sound pressure levels measured were the background noise; see Figure 12.

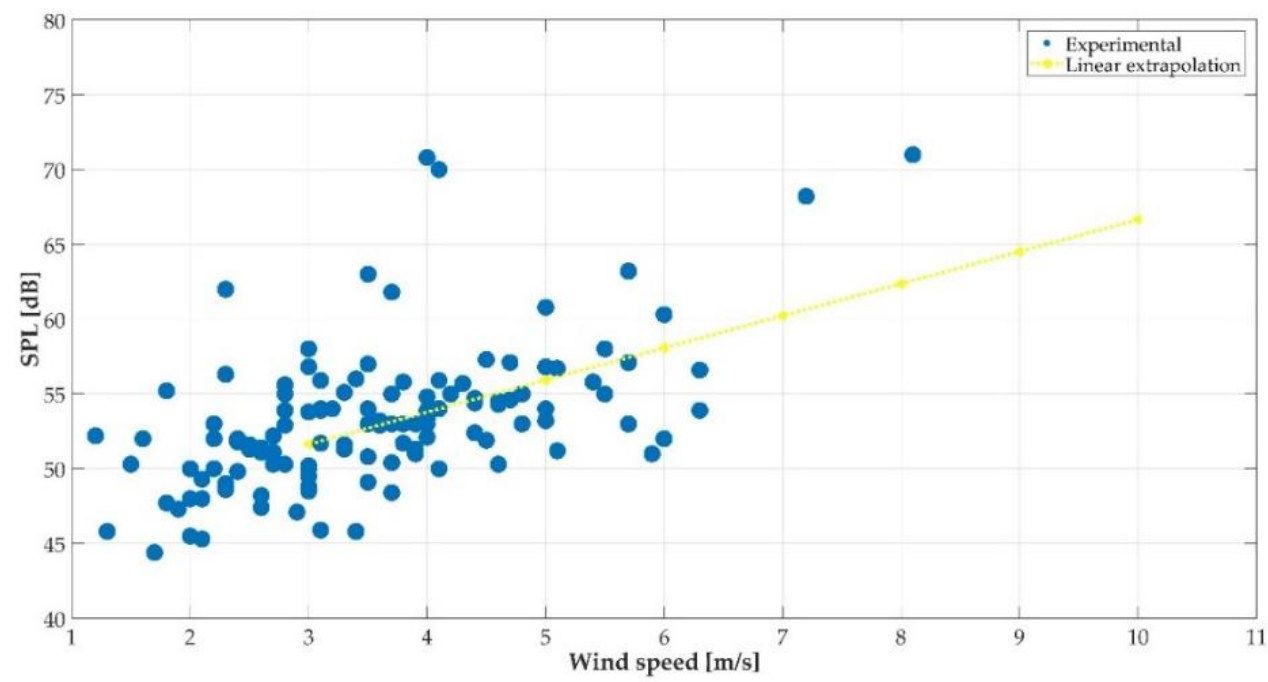

Figure 12. Background sound pressure levels.

Figure 13 shows the sound pressure levels measured with the wind turbine in operation and the background. This figure was constructed from the measurement data presented in Table 2 as an example. The table shows that only wind speeds varying in the range of 1.5 to $8.5 \mathrm{~m} / \mathrm{s}$ were obtained, so we decided to calculate the sound emission trend by Pearson linear extrapolation up to a wind speed of $10 \mathrm{~m} / \mathrm{s}$ (wind speed range recommended by IEC 61400-11).

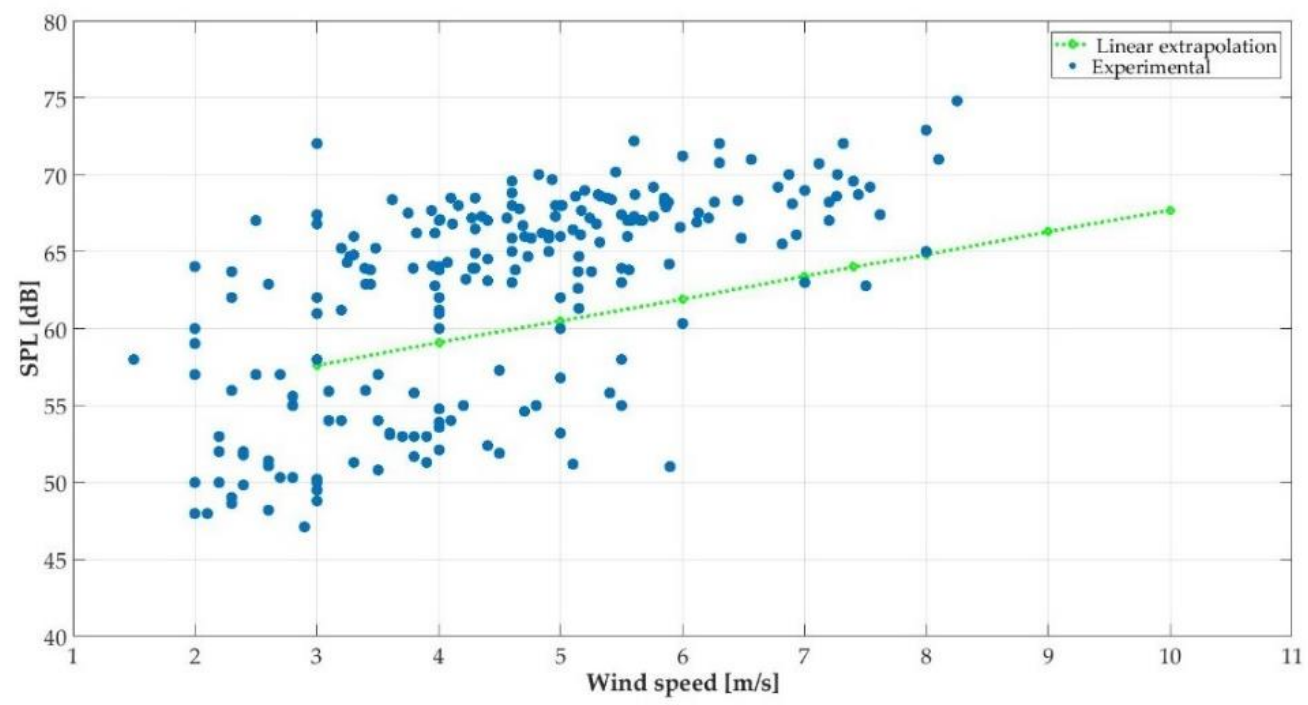

Figure 13. Sound pressure levels produced by the wind turbine and the background.

Table 5 shows the sound pressure levels of the wind turbine calculated by the BPM and BM models and propagated according to the spherical propagation model, as shown in Equation (16), at 8, 10, and $20 \mathrm{~m}$ distance from the wind turbine. 
Table 5. Wind turbine noise propagated by the spherical propagation model.

\begin{tabular}{ccccc}
\hline \multirow{2}{*}{$\begin{array}{c}\text { Wind Speed } \\
{[\mathbf{m} / \mathbf{s}]}\end{array}$} & $\mathbf{1}$ & $\mathbf{5}$ & $\mathbf{1 0}$ & $\mathbf{2 0}$ \\
\cline { 2 - 5 } & \multicolumn{5}{c}{ SPL [dB] } \\
\hline 5 & 78.0 & 59.0 & 58.0 & 51.9 \\
\hline 6 & 80.0 & 61.0 & 60.0 & 53.9 \\
\hline 7 & 81.0 & 62.0 & 61.0 & 54.9 \\
\hline 8 & 81.9 & 63.0 & 61.9 & 55.8 \\
\hline 9 & 82.2 & 64.0 & 62.2 & 56.1 \\
\hline 10 & 82.2 & 64.0 & 62.2 & 56.1 \\
\hline
\end{tabular}

When the emission values calculated with the prediction models were available, it was decided to compare them with the experimental data, since the values of only the wind turbine in operation were not available, as it was not possible to cancel the background sound pressure levels. It was decided to subtract the measured values of the background sound pressure levels (Figure 12) from the values of the sound pressure levels of the wind turbine in operation and the background (Figure 13) by means of a decibel subtraction, thus obtaining the values of the sound pressure levels of only the wind turbine in operation.

Figure 14 shows the data obtained from the experimental measurements of the sound pressure levels of the wind turbine in operation at the corresponding distance established by the IEC 61400-11 standard, which is $8 \mathrm{~m}$, as well as the sound pressure levels of the BPM and BM models, which were propagated to $8 \mathrm{~m}$.

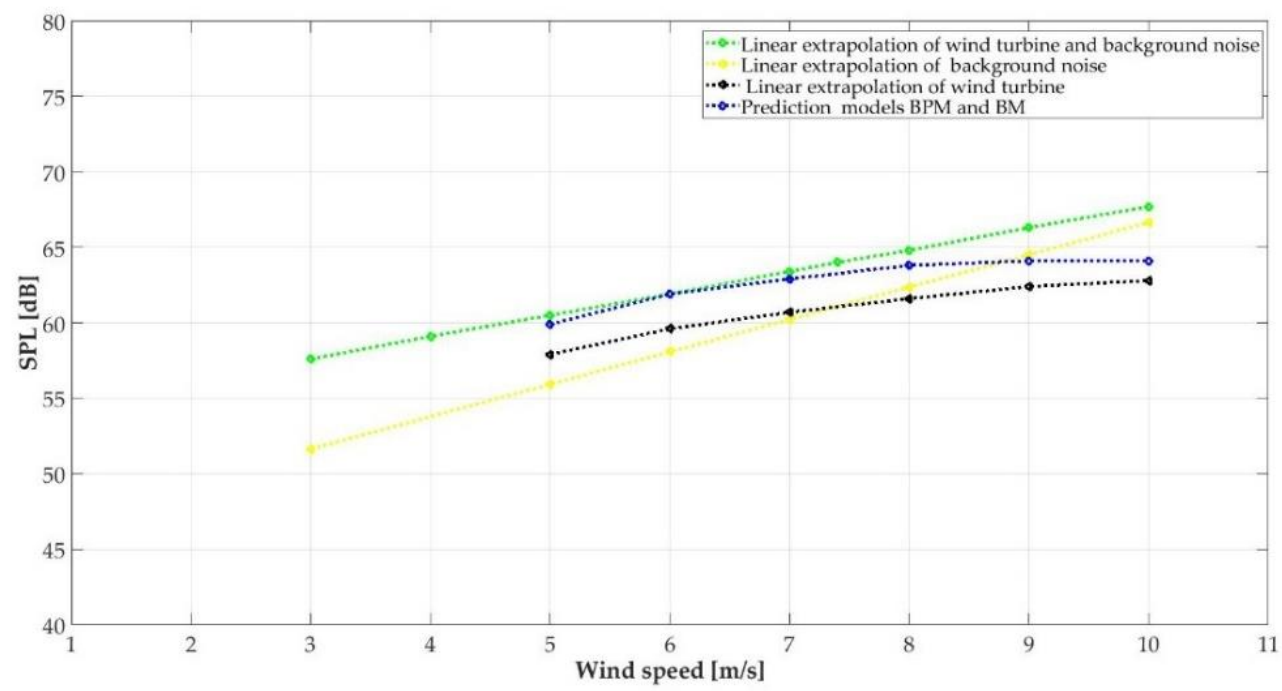

Figure 14. Comparison of numerical and experimental results for the sound pressure levels of the wind turbine in operation.

Table 6 shows the regression and linear extrapolation values obtained from the measurements and compares them with the calculated values of the sound pressure levels emitted by a wind turbine, as shown in Figure 14. We can see in this table the relative error between the values, where the error does not exceed $3.8 \%$, with the largest error corresponding to a wind speed of $6 \mathrm{~m} / \mathrm{s}$. 
Table 6. Validation of sound pressure level prediction models versus wind turbine at $8 \mathrm{~m}$ distance.

\begin{tabular}{cccc}
\hline \multirow{2}{*}{$\begin{array}{c}\text { Wind Speed } \\
{[\mathrm{m} / \mathbf{s}]}\end{array}$} & $\begin{array}{c}\text { SPL [dB] } \\
\text { Experimental Analysis: } \\
\text { Wind Turbine }\end{array}$ & $\begin{array}{c}\text { Theoretical Analysis: } \\
\text { Wind Turbine }\end{array}$ & $\begin{array}{c}\text { Error } \\
{[\%]}\end{array}$ \\
\cline { 2 - 4 } & 57.9 & 59.0 & 3.4 \\
6 & 59.6 & 61.9 & 3.8 \\
7 & 60.7 & 62.9 & 3.6 \\
8 & 61.6 & 63.8 & 3.5 \\
9 & 62.4 & 64.1 & 2.7 \\
10 & 62.8 & 64.1 & 2.0 \\
\hline
\end{tabular}

\section{Conclusions}

This article presents a theoretical and experimental study of the noise generated by a $1 \mathrm{~kW}$ small horizontal axis wind turbine during its operation. The theoretical model used for the noise analysis was shown to be a good tool to estimate the aerodynamic noise of a rotor thanks to its simplicity of implementation and its good approximation compared to the measured data. The comparative study of theoretical and experimental results showed that the BPM and BM methods have a maximum error of $3.8 \%$ corresponding to the rated wind speed of $6 \mathrm{~m} / \mathrm{s}$. However, at low wind speeds, theoretical models fit well to experimental data-for example, in the range from 5 to $8 \mathrm{~m} / \mathrm{s}$. Furthermore, results showed that the largest aerodynamic noise contribution comes from the blade tip vortices.

On the other hand, experimental data showed that the rotor's aerodynamic noise is more evident at low wind speed, because under these conditions, environmental noise is much less than wind turbine noise. By contrast, at high wind speeds, aerodynamic noise and environmental noise have similar noise pressure levels.

Based on the performed analysis, installing and design rules can be proposed to avoid exposure to high noise pressure levels when a small wind turbine is in operation; for example, it is recommended to install small wind turbines at a minimum distance of $20 \mathrm{~m}$ from the receptor; it is also important to carry out the labeling of the sound pressure levels of the small wind turbines as essential technical data before its installation in residential areas. Additionally, a theoretical model can be applied in the early blade design step to consider the aerodynamic noise mitigation. Furthermore, the rotational speed can be limited by active or passive systems to avoid aerodynamic noise for very high wind speed.

The methodology implemented to estimate sound pressure levels can be used in the design of the wind rotor by companies in the low power wind sector (RTO Energy Mexico) to develop wind turbines that operate with the parameters established by the IEC 61400-11 standard. This can encourage the use of low-power wind turbines in urban areas.

As a result of the research obtained in this work, this research group is currently collaborating with the company RTO Energy in the design of wind turbine rotors with capacities from 1 to $10 \mathrm{~kW}$.

At the Universidad del Istmo, a small wind turbine test station is being prepared with all the class I equipment and instruments recommended by the IEC 61400-11 Standard, where the study developed in this work will be implemented, and thus certify the small wind turbines to be installed in residential areas. In addition, the possibility of determining the approximations for predicting noise by considering the 2D and 3D equations is considered, as well as determining the uncertainties of the results.

Author Contributions: Conceptualization, J.R.D., A.R., Q.H.-E., R.C.-A., R.I., O.L., P.L., A.V., L.H., M.-A.P.-M. and A.-J.P.-M.; methodology, J.R.D., A.R., Q.H.-E., R.C.-A., R.I., O.L., P.L., A.V., L.H., M.-A.P.-M. and A.-J.P.-M.; investigation, J.R.D., A.R., Q.H.-E., R.C.-A., R.I., O.L., P.L., A.V., L.H., M.-A.P.-M. and A.-J.P.-M.; writing-original draft preparation, J.R.D., A.R., Q.H.-E., R.C.-A., R.I., O.L., P.L., A.V., L.H., M.-A.P.-M. and A.-J.P.-M.; writing-review and editing, J.R.D., A.R., Q.H.-E., R.C.-A., R.I., O.L., P.L., A.V., L.H., M.-A.P.-M. and A.-J.P.-M. All authors have read and agreed to the published version of the manuscript. 
Funding: This research was funded by Universidad Nacional Autonoma de Mexico (UNAM) attached to the Escuela Nacional de Estudios Superiores unidad Juriquilla within the project PAPIME 103520 entitled "Teaching for the design and evaluation of renewable energy projects for the Renewable Energy Engineering Degree."

Institutional Review Board Statement: Not applicable.

Informed Consent Statement: Not applicable.

Acknowledgments: The authors are grateful for the support provided by the wind energy company RTO, which designs, builds, and markets the small wind turbines, for providing the data of the RTO- $1 \mathrm{~kW}$ wind turbine. Also, for having given the facility in which the group of researchers of this work carry out investigations to select an adequate aerodynamic profile for these characteristic wind regimes in the area of the Isthmus of Tehuantepec. We are grateful to the wind power company ACCIONA, for facilitating the study in the facilities where the wind turbine is located.

Conflicts of Interest: The authors declare no conflict of interest.

\section{References}

1. Schmidt, J.H.; Klokker, M. Health Effects Related to Wind Turbine Noise Exposure: A Systematic Review. PLoS ONE 2014, 9. [CrossRef] [PubMed]

2. Saab-Junior, J.Y. Trailing-Edge Noise Development and Application of a Noise Prediction Tool for the Assessment and Design of Wind Turbine Airfoils; Escola Politécnica da SUniversidade de Sao Paulo: Sao Paulo, Brazil, 2016.

3. Ma, J.; Duan, Y.; Zhao, M.; Lv, W.; Wang, J.; Meng Ke, Q.; Ren, Y. Effect of Airfoil Concavity on Wind Turbine Blade Performances. Shock Vib. 2019. [CrossRef]

4. Zhang, C.Q.; Gao, Z.Y.; Chen, Y.Y.; Dai, Y.J.; Wang, J.W.; Zhang, L.R.; Ma, J.L. Locating and Tracking Sound Sources on a Horizontal Axis Wind Turbine Using a Compact Microphone Array Based on Beamforming. Appl. Acoust. 2019, 146. [CrossRef]

5. Clifton-Smith, M.J. Aerodynamic Noise Reduction for Small Wind Turbine Rotors. Wind Eng. 2010, 34. [CrossRef]

6. Wagner, S.; Bareiß, R.; Guidati, G. Wind Turbine Noise; Springer: Berlin/Heidelberg, Germany, 1996; ISBN 978-3-642-88712-3.

7. Pinder, J.N. Mechanical Noise from Wind Turbines. Wind Eng. 1992, 16, 158-168.

8. Deshmukh, S.; Bhattacharya, S.; Jain, A.; Paul, A.R. Wind Turbine Noise and Its Mitigation Techniques: A Review. Energy Procedia 2019, 160. [CrossRef]

9. Ottermo, F.; Möllerström, E.; Nordborg, A.; Hylander, J.; Bernhoff, H. Location of Aerodynamic Noise Sources from a 200 KW Vertical-Axis Wind Turbine. J. Sound Vib. 2017, 400. [CrossRef]

10. Möllerström, E.; Ottermo, F.; Hylander, J.; Bernhoff, H. Noise Emission of a 200 KW Vertical Axis Wind Turbine. Energies 2016, 9 , 19. [CrossRef]

11. Su, J.; Lei, H.; Zhou, D.; Han, Z.; Bao, Y.; Zhu, H.; Zhou, L. Aerodynamic Noise Assessment for a Vertical Axis Wind Turbine Using Improved Delayed Detached Eddy Simulation. Renew. Energy 2019, 141, 559-569. [CrossRef]

12. Chrysochoidis-Antsos, N.; Amoros, A.V.; van Bussel, G.J.W.; Mertens, S.M.; van Wijk, A.J.M. Wind Resource Characteristics and Energy Yield for Micro Wind Turbines Integrated on Noise Barriers-An Experimental Study. J. Wind Eng. Ind. Aerodyn. 2020, 203, 104206. [CrossRef]

13. Zagubień, A.; Wolniewicz, K. The Impact of Supporting Tower on Wind Turbine Noise Emission. Appl. Acoust. 2019, 155, 260-270. [CrossRef]

14. Göçmen, T.; Özerdem, B. Airfoil Optimization for Noise Emission Problem and Aerodynamic Performance Criterion on Small Scale Wind Turbines. Energy 2012, 46. [CrossRef]

15. Lee, S.; Lee, S. Numerical and Experimental Study of Aerodynamic Noise by a Small Wind Turbine. Renew. Energy 2014, 65. [CrossRef]

16. Zhu, W.J.; Heilskov, N.; Shen, W.Z.; Sørensen, J.N. Modeling of Aerodynamically Generated Noise from Wind Turbines. J. Sol. Energy Eng. 2005, 127. [CrossRef]

17. Oerlemans, S.; Schepers, J.G. Prediction of Wind Turbine Noise and Validation against Experiment. Int. J. Aeroacoustics 2009, 8. [CrossRef]

18. Rodrigues, S.S.; Marta, A.C. On Addressing Wind Turbine Noise with After-Market Shape Blade Add-Ons. Renew. Energy 2019, 140. [CrossRef]

19. Sessarego, M.; Wood, D. Multi-Dimensional Optimization of Small Wind Turbine Blades. Renew. Wind Water Sol. $2015,2$. [CrossRef]

20. Wood, D. Small Wind Turbines; Springer: London, UK, 2011; ISBN 978-1-84996-174-5.

21. Solís-Gallego, I.; Meana-Fernández, A.; Fernández Oro, J.M.; Argüelles Díaz, K.M.; Velarde-Suárez, S. LES-Based Numerical Prediction of the Trailing Edge Noise in a Small Wind Turbine Airfoil at Different Angles of Attack. Renew. Energy 2018, 120. [CrossRef]

22. Taylor, J.; Eastwick, C.; Lawrence, C.; Wilson, R. Noise Levels and Noise Perception from Small and Micro Wind Turbines. Renew. Energy 2013, 55. [CrossRef] 
23. Lee, H.; Lee, D.-J. Low Reynolds Number Effects on Aerodynamic Loads of a Small Scale Wind Turbine. Renew. Energy 2020, 154. [CrossRef]

24. NOM-081-ECOL-1994: Límites Máximos Permisibles de Emisión de Ruido de Las Fuentes Fijas; CDMX, Diario Oficial de la Ferderacion: Mexico City, Mexico, 1994.

25. Brooks, T.F.; Pope, D.S.; Marcolini, M.A. Airfoil Self-Noise and Prediction; National Aeronautics and Space Administration: Washington, DC, USA, 1989.

26. Bhargava, V.; Samala, R. Effect of Boundary Layer and Rotor Speed on Broadband Noise from Wind Turbines. J. Aerosp. Technol. Manag. 2019. [CrossRef]

27. Standard IEC 61400-11: Wind Turbine Generator Systems- Part 11: Acoustic Noise Measurement Techniques; International Electrotechnical Commission: Geneva, Switzerland, 2003.

28. Lowson, M.V. Assessment and Prediction of Wind Turbine Noise; IAEA: Bristol, UK, 1993.

29. Grosveld, F.W. Prediction of Broadband Noise from Horizontal Axis Wind Turbines. J. Propuls. Power 1985, 1. [CrossRef]

30. Brooks, T.F.; Marcolini, M.A. Airfoil Tip Vortex Formation Noise. AIAA J. 1986, 24. [CrossRef]

31. Rogers, A.L.; Manwell, J.F.; Wright, S. Wind Turbine Acoustic Noise; Renewable Energy Research Laboratory: Amherst, MA, USA, 2002.

32. Vers, I.L.; Beranek, L.L. (Eds.) Noise and Vibration Control Engineering; John Wiley \& Sons, Inc.: Hoboken, NJ, USA, 2005; ISBN 9780470172568.

33. RTO Energy. Available online: www.rtoenergy.com.mx (accessed on 8 January 2021).

34. Echeverri-Londoño, C.A.; González-Fernández, A.E. Model for the Prediction of Noise from Wind Turbines. Rev. Fac. Ing. Univ. Antioq. 2018. [CrossRef]

35. Lopez-Villalobos, C.; Rodriguez-Hernandez, O.; Campos-Amezcua, R.; Hernandez-Cruz, G.; Jaramillo, O.; Mendoza, J. Wind Turbulence Intensity at La Ventosa, Mexico: A Comparative Study with the IEC61400 Standards. Energies 2018, $11,3007$. [CrossRef]

36. Cadenas, E.; Campos-Amezcua, R.; Rivera, W.; Espinosa-Medina, M.A.; Méndez-Gordillo, A.R.; Rangel, E.; Tena, J. Wind Speed Variability Study Based on the Hurst Coefficient and Fractal Dimensional Analysis. Energy Sci. Eng. 2019, 7. [CrossRef] 